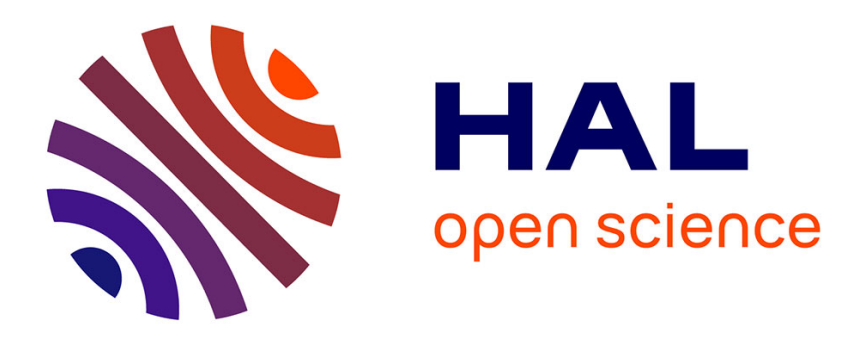

\title{
Impact of upper-level jet-generated inertia-gravity waves on surface wind and precipitation
}

C. Zülicke, D. H. W. Peters

\section{To cite this version:}

C. Zülicke, D. H. W. Peters. Impact of upper-level jet-generated inertia-gravity waves on surface wind and precipitation. Atmospheric Chemistry and Physics Discussions, 2007, 7 (6), pp.15873-15909. hal-00303172

\section{HAL Id: hal-00303172 \\ https://hal.science/hal-00303172}

Submitted on 13 Nov 2007

HAL is a multi-disciplinary open access archive for the deposit and dissemination of scientific research documents, whether they are published or not. The documents may come from teaching and research institutions in France or abroad, or from public or private research centers.
L'archive ouverte pluridisciplinaire HAL, est destinée au dépôt et à la diffusion de documents scientifiques de niveau recherche, publiés ou non, émanant des établissements d'enseignement et de recherche français ou étrangers, des laboratoires publics ou privés. 
Atmos. Chem. Phys. Discuss., 7, 15873-15909, 2007

www.atmos-chem-phys-discuss.net/7/15873/2007/

(C) Author(s) 2007. This work is licensed

under a Creative Commons License.

Impact of

inertia-gravity waves

on wind and

precipitation

\section{Impact of upper-level jet-generated inertia-gravity waves on surface wind and precipitation}

C. Zülicke and D. Peters

\section{Zülicke ${ }^{1, *}$ and D. H. W. Peters ${ }^{1}$}

${ }^{1}$ Leibniz Institute of Atmospheric Physics, Kühlungsborn, Germany "now at: Leibniz Institute for Baltic Sea Research, Warnemünde, Germany

Received: 1 October 2007 - Accepted: 6 November 2007 - Published: 13 November 2007

Correspondence to: C. Zülicke (christoph.zuelicke@io-warnemuende.de)

Title Page

Abstract

Introduction

Conclusions

References

Tables

Figures

14

$>1$

4

Back 


\section{Abstract}

A meteorological case study for the impact of inertia-gravity waves on surface meteorology is presented. The large-scale environment from 17 to 19 December 1999 was dominated by a poleward breaking Rossby wave transporting subtropical air over the

5 North Atlantic Ocean upward and north-eastward. The synoptic situation was characterized with an upper tropospheric jet streak passing Northern Europe. The unbalanced jet spontaneously radiated inertia-gravity waves from its exit region. Near-inertial waves appeared with a horizontal wavelength of about $200 \mathrm{~km}$ and an apparent period of about $12 \mathrm{~h}$. These waves transported energy downwards and interacted with largescale convection.

This configuration is simulated with the nonhydrostatic Fifth-Generation Mesoscale Model. Together with simplified runs without orography and moisture it is demonstrated that the imbalance of the jet (detected with the cross-stream ageostrophic wind) and the deep convection (quantified with the latent heat release) are forcing inertia-gravity 15 waves. This interaction is especially pronounced when the upper tropospheric jet is located above a cold front at the surface and supports deep frontal convection. Weak indication was found for triggering post-frontal convection by inertia-gravity waves.

The realism of model simulations was studied in an extended validation study for the Baltic Sea region. It included observations from radar (DWDPI, BALTRAD), satellite (GFZGPS), weather stations (DWDMI) and assimilated products (ELDAS, MESAN). The detected spatio-temporal patterns show wind pulsations and precipitation events at scales corresponding to those of inertia-gravity waves. In particular, the robust features of strong wind and enhanced precipitation near the front appeared with nearly the same amplitudes as in the model. In some datasets we found indication for periodic variations in the post-frontal region.

These findings demonstrate the impact of upper tropospheric jet-generated inertiagravity waves on the dynamics of the boundary layer. It also gives confidence to models, observations and assimilation products for covering such processes. In an applica-

\section{Impact of}

inertia-gravity waves

on wind and

precipitation

C. Zülicke and D. Peters

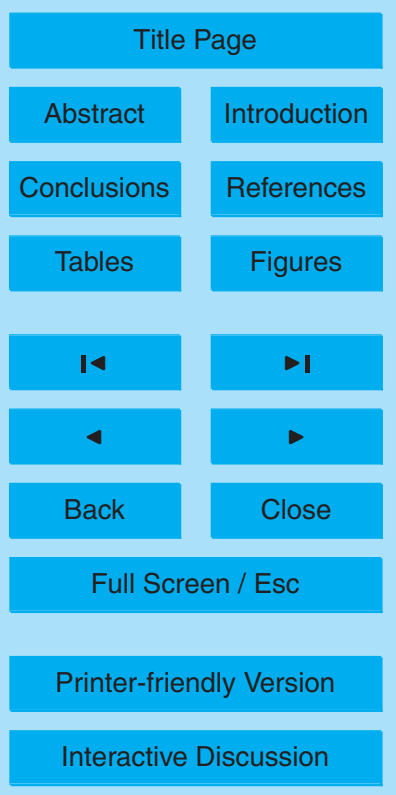


tion for the Gotland Basin in the Baltic Sea, the implications of such mesoscale events on air-sea interaction and energy and water budgets are discussed.

\section{Introduction}

Inertia-gravity waves (IGW for short) are sub-synoptic features of the atmospheric dy5 namics. During their evolution, IGWs propagate signals over relatively long distances, both in the horizontal and vertical. Consequently, regional weather events may be linked to processes in the upper levels of the atmosphere. They are essential for the mean global circulation of the middle atmosphere (e.g. Fritts and Alexander, 2003; Holton, 1992). In the lower troposphere, regional weather events such as wind gusts or deep convection are sometimes closely connected with IGWs (Bosart and Cussen, 1973; Uccellini, 1975; Bosart et al., 1998). Local fluctuations due to IGWs may modulate the wind field, which drives the air-sea exchange and mixing of the surface water. The influence of upper tropospheric jet-generated IGWs on moist convection is another aspect, which may lead to sudden large rates of rainfall. Compilations of precipitation observations for the Baltic Sea region. Rutgersson et al. (2001) show, that different methods scatter by $10-20 \%$ on a monthly and basin-wide scale. The major reason for this uncertainty is the spatio-temporal variability of precipitation. The study of IGW dynamics could attribute to an improved understanding of the space and time scales of such precipitation events.

20 The appearance of IGWs on the planetary scale has been related to the life cycle of baroclinic Rossby waves by O'Sullivan and Dunkerton (1995). In their in experiments with a global circulation model increase IGW activity was found at the north-western ridge of a poleward breaking Rossby wave (abbreviated with RWB). Such a situation is often present in winter time over the North Atlantic Ocean/European region. It is asand Waugh, 1996). Accordingly, there are locations with especially sharp gradients between subtropical and polar air masses. This induces not only increased cyclonic

\section{Impact of}

inertia-gravity waves

on wind and

precipitation

C. Zülicke and D. Peters

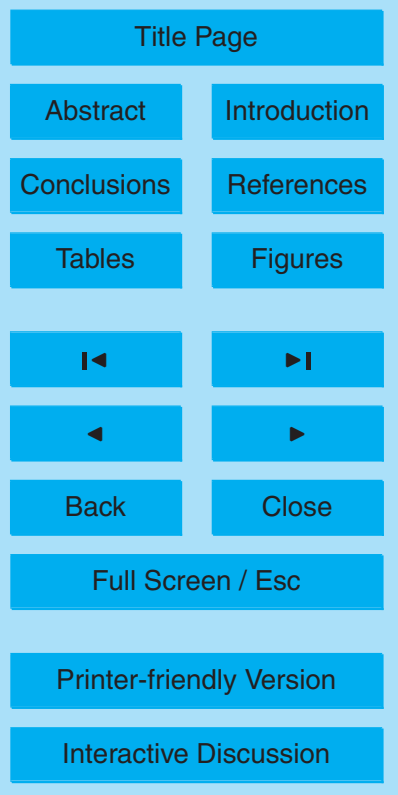

EGU 
activity, but also jet streaks in the tropopause region. Uccellini and Koch (1987) have figured out, in situations with a warm front located just beneath the exit region of such an upper tropospheric jet strong IGW activity may be expected.

In such configurations IGWs have occasionally been observed (Guest et al., 2000; 5 Plougonven et al., 2003; Thomas et al., 1999; Peters et al., 2003; Zülicke and Peters, 2007), but systematic studies of their impact on the regional weather are rare. The Cooperative Convective Precipitation Experiment (CCOPE), conducted 1981 in the Rocky Mountains (Koch and Golus, 1988), was one outstanding field experiment. Based on the mesoscale observation network with a station distance of $7 \mathrm{~km}$ a conceptual model 10 has been developed, which allocates the position of deep convection in a traveling IGW. The upward velocity fluctuations associated with the IGW induce additional updrafts, which may initiate deep convection in a conditionally unstable environment. In turn, the convective dynamics may serve as an IGW source and establishes a kind of feed-back to the triggering IGW.

15 The quantification of this conceptual model requires the identification of the relevant processes and the diagnosis of suitable measures for IGW effects. A large variety of processes may serve as IGW source: this is unbalanced jet streaks, frontal systems, convection and orography. In situations with a RWB, imbalances in the exit regions of upper tropospheric jet streak may spontaneously radiate IGWs. The source intensity of such jet-generated IGWs can be quantified with the Lagrangian wind speed tendency (Zhang et al., 2000). For the description of IGWs during moist convection different processes are discussed: adiabatic heating, nonlinear advection, flow deformation by convective cloud towers (the so-called "obstacle effect" or "moving mountain effect"), oscillations of air parcels around their level of neutral buoyancy or nonstationarity of the heat sources (Lane et al., 2001; Alexander and Holton, 2004). A joint description of both upper tropospheric jets and moist convection including the role of IGWs is still pending. Both generation processes contribute to the IGW in the upper atmospheric layers. Zülicke and Peters (2006) found in a case study that $36 \%$ of the stratospheric IGW activity was related to the upper tropospheric jet and $26 \%$ to moist convection.

\section{Impact of \\ inertia-gravity waves on wind and precipitation}

C. Zülicke and D. Peters

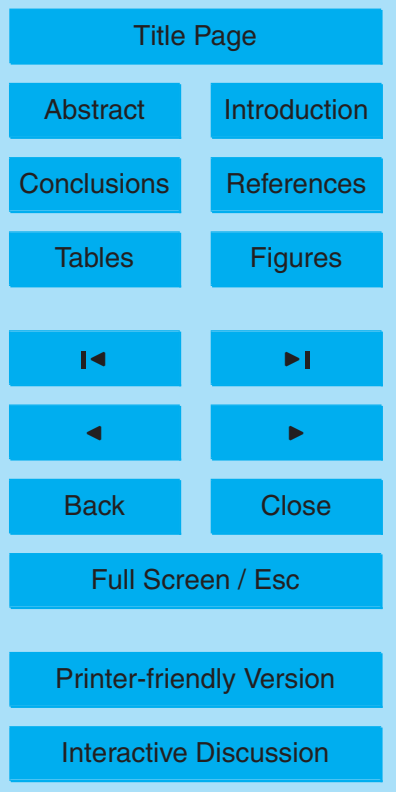


The proper quantitative description of IGWs is important for global circulation models, which do not resolve the complete IGW spectrum (Kim et al., 2003). Hence, the highfrequency part of the IGW spectrum must be taken into account with parameterizations. In order to formulate them properly, observational data and well-validated numerical 5 simulations are required.

Mesoscale numerical modeling on the regional scale has proven capability to simulate IGW generation induced by the upper tropospheric jet (Zhang, 2004; Zülicke and Peters, 2006), convection and fronts (Reeder and Griffiths, 1996; Lane et al., 2001, 2004 ) in process studies. The advantage of using regional nested models is the possi10 bility to cover scales over order of magnitudes with a successive increasing resolution from domain to domain. In a case study with a high-resolution mesoscale model the simulations were validated with upper air radiosonde observations. A corresponding validation exercise on IGW amplitudes in the surface layer is required and another aim of this study.

In a case study a poleward RWB event was observed and modeled, which took place over the North-European/Baltic Sea region from 17 to 19 December 1999 (Peters et al., 2003; Zülicke and Peters, 2006). Here, we focus on the process of IGW generation from the upper tropospheric jet, their downward propagation and impact on the boundary layer over the Baltic Sea. The Southern Baltic is supposed to be a place with especially intense jet-generated IGWs. This is due to the location of the upper tropospheric jet streak over northern Europe with its exit region over the Mecklenburg Bight while mountain waves are unimportant for this westerly flow. The chance to sample IGWs and related effects in the wind and precipitation fields is high in the Baltic Sea region because of the dense observational network. Lots of data are available 25 from radar, satellite and automated weather stations around the coast. Data assimilation to circulation models is a tool to generate meteorological fields over the ocean, where observations are sparse in comparison with land. A detailed inter-comparison of mesoscale models Jacob et al. (2001) indicated that the scattered and localized appearance of convective precipitation is difficult to be taken into account. The study

\section{Impact of}

inertia-gravity waves

on wind and

precipitation

C. Zülicke and D. Peters

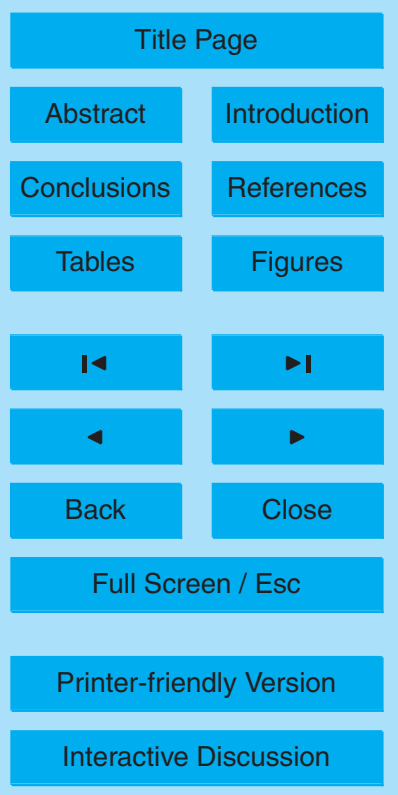


of IGW dynamics in the frame of upper tropospheric jet streaks and moist convection could attribute to an improved understanding of the space and time scales of such precipitation events. The joint analysis of observations and simulations is expected to confirm the relevance of IGWs and to validate the methods.

5 The paper is organized as follows: Sect. 2 is devoted to the introduction of the data base including a sketch of the meteorological situation, analyses, radar, satellite, weather station data and assimilated products. Spatio-temporal patterns of IGWs and related wind pulsations and precipitation events are subject of Sect. 3. It includes detailed process studies, diagnosis of simulations, observations and assimilations and 10 their mutual validation. The discussion in Sect. 4 focuses on the numerical simulation and observation of IGWs, the interaction between IGWs and convection, and their consequences for air-sea exchange. A summary is presented in the final section.

\section{Data base and meteorological background}

\subsection{ECMWF analyses (ECANA)}

15 ECMWF analyses are generated with the Integrated Forecast System with a resolution of T319L60 corresponding to $\Delta s($ ECANA) $\sim 63 \mathrm{~km}$ and $\Delta z$ (ECANA) $\sim 640 \mathrm{~m}$ at tropopause levels. They have been extracted from archive each $6 \mathrm{~h}$ with full horizontal resolution on 21 levels between 1000 and $1 \mathrm{hPa}$. These data contained standard meteorological parameters including water vapor mixing ratio but no precipitation rates.

\subsection{Meteorological background}

From 17 to 19 December 1999 a field campaign was run at Kühlungsborn $\left(54.1^{\circ} \mathrm{N}\right.$, $\left.11.8^{\circ} \mathrm{E}\right)$, which aimed to highlight the relation between RWB and IGWs in the stratosphere (see Fig. 1a). The synoptic situation during this time is exemplified with ECANA data. In a map of the mean sea level pressure $\left(p_{\text {slv }}\right.$, Fig. $\left.1 \mathrm{~b}\right)$ a large high-pressure cen-

Impact of

inertia-gravity waves

on wind and

precipitation

C. Zülicke and D. Peters

Title Page

Abstract

Introduction

Conclusions

Tables

References

Figures

14

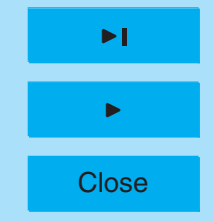

Full Screen / Esc

Printer-friendly Version

Interactive Discussion 
subtropical warm and moist air is advected to Northern Europe. It forms an extended front moving into south-eastern direction as can be seen in the $500 \mathrm{hPa}$ map of water vapor mixing ratio $\left(q_{v}\right)$. This process is also related to increased gradients in potential vorticity at higher atmospheric levels. At the $300 \mathrm{hPa}$ pressure surface (Fig. 1c)

5 strong jets are found along these air mass boundaries and a minimum in Ertel potential vorticity (EPV) of about 0.50 practical vorticity units $\left(P V U=\mathrm{K} \mathrm{kg}^{-1} \mathrm{~m}^{2} \mathrm{~s}^{-1}\right)$ at $330 \mathrm{~K}$. Such configuration is typical for a poleward RWB (Peters and Waugh, 1996). A westerly jet streak is found over the North-East Atlantic Ocean with more then $60 \mathrm{~m} \mathrm{~s}^{-1}$ wind speed $\left(u_{h}\right)$ in its centre. This upper tropospheric jet has its exit region just above 10 the Southern Baltic, thus favoring the generation of IGWs in this region (Uccellini and Koch, 1987). A high of upper tropospheric EPV of about $7.4 \mathrm{PVU}$ is found at $\left(65^{\circ} \mathrm{N}\right.$, $40^{\circ} \mathrm{E}$ ), corresponding to a surface pressure low of about $965 \mathrm{hPa}$. Both PV anomalies are influencing the Großwetterlage (synoptic situation) of the following days over North-Western Europe. Starting with 00:00 UTC 17 December 1999, cold and dry air 15 of polar origin is present. During this day, warm and moist air is taking over, which has been advected from the subtropics along northern edge of the Atlantic high including the passage of a large-scale warm front from the West. This phase ends with a cold front arrival at about 12:00 UTC 17 December 1999. A second phase with advection of Atlantic air from westerly directions starts at about 06:00 UTC 18 December 1999 and 20 extends until 00:00 UTC 19 December 1999, when a change to northerly winds takes place.

\subsection{Fifth generation Mesoscale Model (MM5)}

The Fifth-Generation Mesoscale Model (MM5) has been set up in order to simulate IGWs, their generation, propagation and dissipation, including the effect on the local 25 weather. The MM5 was developed by NCAR (Boulder, Colorado) and the Pennsylvania State University (Dudhia, 1993; Grell et al., 1995). It integrates the nonhydrostatic dynamics and is implemented on a staggered grid. The high-resolution run (referred to as "MM5") has been set up as follows: Three nested domains have been defined Fig. 1a),

\section{Impact of}

inertia-gravity waves on wind and precipitation

C. Zülicke and D. Peters

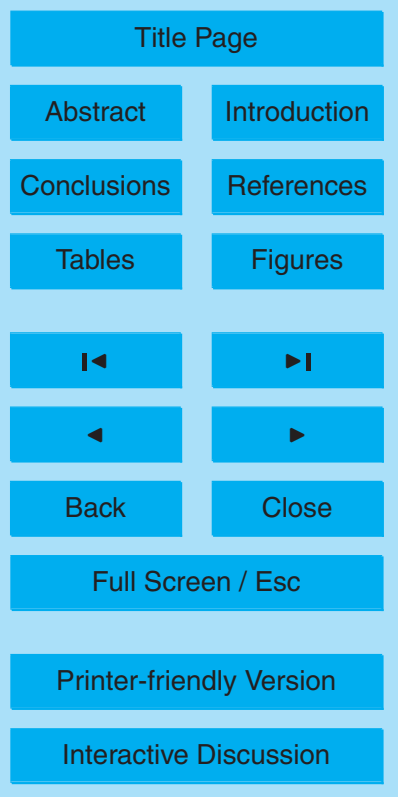

EGU 
which cover an area of about $9000 \mathrm{~km} \times 7000 \mathrm{~km}$. The domains have a horizontal resolution of $\Delta s(\mathrm{MM} 5)=72 / 24 / 8 \mathrm{~km}$ and a vertical resolution of $\Delta z(\mathrm{MM} 5)=100 \mathrm{~m}$. For the parameterization of subgrid physical processes the planetary boundary layer module from the Medium-Range Forecast Model was used, Grell-parameterization of cumulus 5 convection and a Dudhia ice scheme for the microphysics. The model was started at 00:00 UTC 16 December 1999. For the construction of initial and boundary conditions ECMWF analyses were used. They were provided at the lower and lateral boundaries of the largest domain - no data assimilation in the model interior was involved. Hourly model output is used for the present study.

10 For a process study idealized runs have been set up: with and without moisture and latent heating (MM5WET and MM5DRY). Both were run with two domains and medium resolution $(\Delta s($ MM5WET, MM5DRY $)=72 / 24 \mathrm{~km}$ and $\Delta z($ MM5WET, MM5DRY $)=250 \mathrm{~m})$. The terrain height was set to Zero.

\subsection{Mesoscale Analysis System (MESAN)}

15 The Mesoscale Analysis System (MESAN) has been developed at the Swedish Meteorological and Hydrological Institute (Häggmark et al., 2000). It uses the optimal interpolation technique to generate merged analyses from radars, automatic and synoptic stations, satellites and first guess fields from the High-Resolution Regional Model (HIRLAM). The HIRLAM data have been generated with a horizontal resolution of

$20 \Delta s(\mathrm{HIRLAM}) \approx 44 \mathrm{~km}$ and 31 levels corresponding to $\Delta z(\mathrm{HIRLAM}) \approx 550 \mathrm{~m}$. The MESAN system is in operation since October 1996 and provides hourly data on a $22 \mathrm{~km}$ grid.

\subsection{European Land Data Assimilation System (ELDAS)}

In the frame of the European Land Data Assimilation System (ELDAS) precipitation fields have been created for the Baltic Sea region (Rubel, 2004). Observations from 2520000 rain gauges and radar imagery from the Central European Radar Network (CERAD) and the Baltic Radar Network (BALTRAD) are analyzed with the Precipitation

\section{Impact of}

inertia-gravity waves

on wind and

precipitation

C. Zülicke and D. Peters

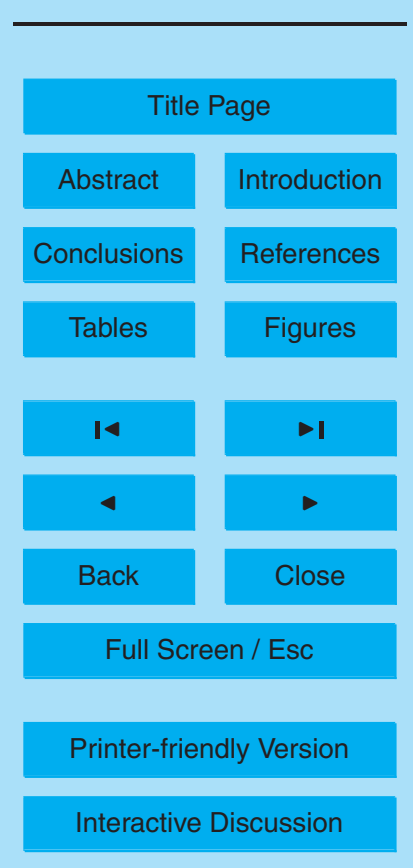


Correction and Analysis (PCA) model (Rubel and Hantel, 2001). For background data an experimental ECMWF 40-year Reanalysis Project (ERA40) run with T159L60 spectral resolution has been used. This corresponds to a resolution of $\Delta s($ ERA40) $\approx 126 \mathrm{~km}$ and $\Delta z$ (ERA40) $\approx 40 \mathrm{~m}$. Data are available from October 1999 to December 2000 5 every $3 \mathrm{~h}$ on a 0.2 latitude/longitude grid $(\Delta s(E L D A S) \approx 22 \mathrm{~km})$.

\subsection{BALTEX radar network (BALTRAD)}

BALTRAD is the radar network for the Baltic Sea Experiment (BALTEX) (Koistinen and Michelson, 2002). It is in operation since October 1999 and provides radar reflectivity composites with $2 \mathrm{~km}$ resolution each $15 \mathrm{~min}$ together with 3-and 12-hourly accumulated precipitation. The data base is formed from about 30 weather radars in Norway, Sweden, Finland, Denmark, Germany and Poland. After a quality control, the pixel closest to the earth surface is taken for the reflectivity composite. Precipitation rates are estimated using a gauge-to-radar ratio which is determined every $12 \mathrm{~h}$. The gauges are systematically corrected with the Dynamic Correction Model (Michelson and Koistinen, 2000) accounting for flow distorsion and instrument-specific corrections using background data from MESAN.

\subsection{DWD international radar composites (DWDPI)}

An international radar composite is compiled by the Deutsche Wetterdienst (DWD) from local radar images from Brussels (Belgium) and Romo (Denmark) together with images from Germany, Austria, Switzerland, France, the Netherlands, Great Britain and the Czech Republic (DWD, 2006). For the composite the value nearest to ground is taken. It is provided with $4 \mathrm{~km}$ resolution every $15 \mathrm{~min}$.

\subsection{GFZ GPS atmosphere soundings (GFZGPS)}

GPS (Global Positioning System) data of a German ground receiver network are used

\section{Impact of}

inertia-gravity waves

on wind and

precipitation

C. Zülicke and D. Peters

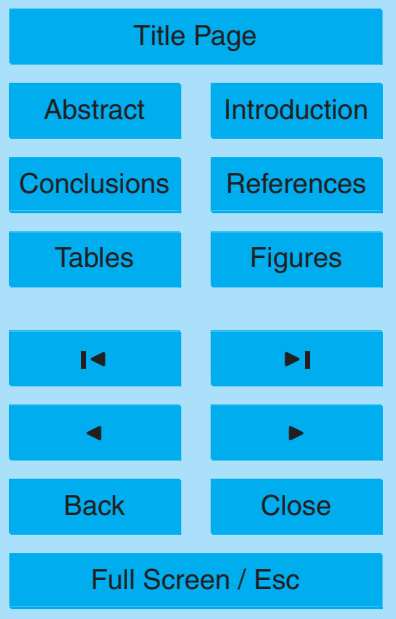

Printer-friendly Version

Interactive Discussion 
al., 2004). The data are operationally processed; corresponding analysis results are provided by GFZ. Currently (as of mid 2007) about 220 stations are included in the processing. The GPS atmosphere sounding activities started at GFZ within the German Helmholtz Association's strategy fund project GASP (GPS Atmosphere Sounding

5 Project (see, e.g., Reigber et al., 2002). For the December 1999 campaign hourly GFZGPS data were available for Warnemünde $\left(54.2^{\circ} \mathrm{N}, 12.1^{\circ} \mathrm{E}\right)$ and five more German stations.

\subsection{DWD MIRIAM/AFMS2 automated weather stations (DWDMI)}

For validation purposes, wind and precipitation data from MIRIAM/AFMS2 automated weather stations from the DWD were used. These were available every $10 \mathrm{~min}$ from 214 German stations including Warnemünde.

\section{Results}

\subsection{MM5 simulation of IGW patterns}

A snapshot from the MM5 simulation for 18:00 UTC 17 December 1999 is discussed in the following. The dense geopotential height contours induce a jet streak at $300 \mathrm{hPa}$, approaching the Baltic Sea from west (see Fig. 2a). The arriving air masses are of subtropical origin and have been advected at the north-eastern edge of the highpressure centre in the North-Atlantic (see Fig. 1b). Perpendicular to the major wind direction an extended band of height-integrated precipitable water (including rain, snow and graupel, $W_{p}=\int d z q_{p}$ ) is found, which is denoted with C2 (convective event number two, at distance $s \approx 1750 \mathrm{~km}$ ). Along a cross section through Warnemünde two other localized precipitable water clusters are found (C3 and C4) (see Fig. 2b). While the C2 event near Warnemünde (at $s \approx 1700 \mathrm{~km}$ ) extends as high as $5 \mathrm{~km}$, the event C3 (at $s \approx 1200 \mathrm{~km}$ ) contains more precipitable water but is more localized and C4 (at

Impact of

inertia-gravity waves

on wind and

precipitation

C. Zülicke and D. Peters

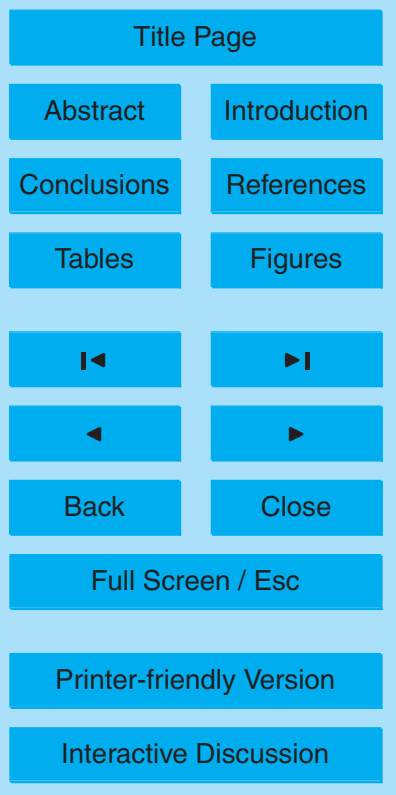


$s \approx 400 \mathrm{~km}$ ) is even weaker and smaller. It is noteworthy, that a smaller band with precipitable water is found in the wake of the big front, which appears in the cross section at $s \approx 1600 \mathrm{~km}$.

In order to resolve possible relations between the upper-level jet streak and the 5 surface wind and precipitation patterns IGW structures are shown in a $300 \mathrm{hPa}$ map (Fig. 2c) and the Warnemünde cross section (Fig. 2d). A complex three-dimensional structure is appearing in the horizontal divergence $(\delta=\partial u / \partial x+\partial v / \partial y)$, which is used to indicate the IGWs. Localized regions with short horizontal and long vertical wavelength can be found above mountains. In the map these are Greenland $\left(65-70^{\circ} \mathrm{N}\right.$, $\left.1015-20^{\circ} \mathrm{W}\right)$, the Scottish highlands $\left(55-60^{\circ} \mathrm{N}, 0-10^{\circ} \mathrm{W}\right)$, the Scandinavian ridge $(60-$ $\left.65^{\circ} \mathrm{N}, 5-10^{\circ} \mathrm{E}\right)$ and the Alps $\left(45-52^{\circ} \mathrm{N}, 5-20^{\circ} \mathrm{E}\right)$. Patterns over the Scottish Highlands are also contained in the cross section (Fig. 2d) and are denoted with $\mathrm{M}$ (for mountain waves). The three convection events show also in the divergence structures, especially clear for C3: this is a zone of convergence $(\delta<0)$ below $2 \mathrm{~km}$ height and a zone of di15 vergence $(\delta>0)$ between 2 and $6 \mathrm{~km})$ with maximal amplitudes of $\delta \approx 8 \times 10^{-5} \mathrm{~s}^{-1}$. It is also interesting to note, that there appears a tower of downward sloping phase lines right above $\mathrm{C} 3$, similar to the mountain waves. A third class of waves appears as a combination of downward inclined phases in the stratosphere and upward inclined in the troposphere. These IGWs appear more clearly after smoothing the divergence over $100 \mathrm{~km}$ (see Fig. $2 \mathrm{e}$ and f). Three of such jet-generated IGWs can be found in Fig. $2 \mathrm{f}$ at the upper tropospheric jet level (height $z \approx 9 \mathrm{~km}$ ) at $s \approx 2100 \mathrm{~km}, 1750 \mathrm{~km}$ and $1250 \mathrm{~km}$ and are denoted with $\mathrm{J} 2, \mathrm{~J} 3$ and $\mathrm{J} 4$. Solid lines along regions with positive divergence $(\delta>0)$ suggest a connection between the jet and wave-like structure above and below. In the stratosphere five crests can be found in the height region $z \approx 13-17 \mathrm{~km}$ between $25 \mathrm{~J} 2$ and J4. They suggest a horizontal wavelength of $\lambda_{h}(\mathrm{MM} 5) \approx 220 \mathrm{~km}$ and a vertical wavelength of $\lambda_{z}(\mathrm{MM} 5) \approx 3.6 \mathrm{~km}$. Using the dispersion relation for hydrostatic inertia-

\section{Impact of}

inertia-gravity waves

on wind and

precipitation

C. Zülicke and D. Peters

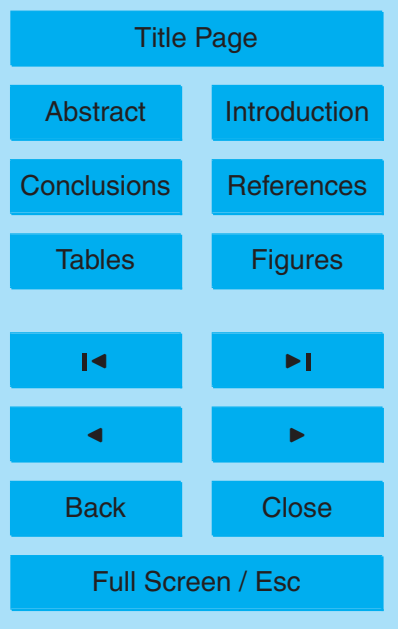

Printer-friendly Version

Interactive Discussion 
gravity waves the intrinsic frequency of

$\omega_{i}=\left(f^{2}+N^{2} \frac{k_{h}^{2}}{k_{z}^{2}}\right)^{1 / 2} \approx \frac{2 \pi}{7.1 \mathrm{~h}}(\mathrm{MM} 5)$

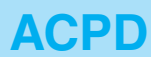

can be estimated $\left(f=1.4 \times 10^{-4} \mathrm{~s}^{-1}, N=1.2 \times 10^{-2} \mathrm{~s}^{-1}\right)$. For a mean tropospheric wind in IGW direction of $u_{\|}=\left(k_{x} u+k_{y} v\right) / k_{h} \approx-15 \mathrm{~m} \mathrm{~s}^{-1}$ the Doppler relation

$5 \quad \omega_{a}=\omega_{i}+k_{h} u_{\|} \approx-\frac{2 \pi}{9.3 \mathrm{~h}}(\mathrm{MM} 5)$

determines the apparent period. These numbers are similar to those found in Zülicke and Peters (2006), where imbalances in the upper tropospheric jet exit region have been identified as their energy source. Inspection of the tropospheric divergence patterns shows that not all stratospheric J-patterns reach the surface. Forward inclined 10 positive phases are found for $\mathrm{J} 4$ which are in positive interference with the divergent zone of $C 3$ at $(s \approx 1100 \mathrm{~km}, z \approx 4.5 \mathrm{~km})$. Some of the forward inclined positive phase lines of $\mathrm{J} 2$ and $\mathrm{J} 3$ seem to be cut by backward inclined negative phase lines. The latter have a V-shaped form localized around $s \approx 1800 \mathrm{~km}$ and $1600 \mathrm{~km}$ and could be attributed to convective of frontal activity.

\subsection{MM5 simulation of IGW processes}

In order to resolve this complex pattern idealized MM5 simulations have been performed. The MM5 was run with medium resolution to keep the computational effort down and without topography to exclude the formation of mountain waves. For the isolation of convective processes, the model was run dry (without any moisture, MM5DRY) and wet (with moisture and microphysics including latent heat release, MM5WET). The 100-km-smoothed divergence is shown for a cross section through the dry run in Fig. 3a (MM5DRY). For a quantitative interpretation the cross-stream ageostrophic

Impact of inertia-gravity waves on wind and precipitation

C. Zülicke and D. Peters

Title Page

Abstract

Conclusions

Tables References

Figures

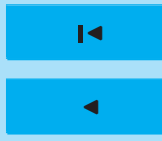

$>1$

Back

Close

Full Screen / Esc

Printer-friendly Version

Interactive Discussion 
wind

$u_{*}=\frac{u_{a} v_{g}-v_{a} u_{g}}{\left(u_{g}^{2}+v_{g}^{2}\right)^{1 / 2}}=-\frac{1}{f} \frac{d u_{h, g}}{d t}$

is superimposed. It is closely associated to the tendency of the geostrophic wind speed $\left(u_{h, g}=\left(u_{g}^{2}+v_{g}^{2}\right)^{1 / 2}\right)$ and serves as a measure for the imbalance of the jet streak. The 5 maximal value of $u_{*}(\mathrm{MM} 5 \mathrm{DRY}) \approx 3.5 \mathrm{~m} \mathrm{~s}^{-1}$ can be associated with a divergence over the extension of the imbalance $\left(L_{*} \approx 217 \mathrm{~km}\right)$ as

$\delta_{*}($ jet $) \propto \frac{u_{*}}{L_{*}}$

For the dry run a value of jet-generated divergence $\delta_{*}\left(\right.$ jet, MM5DRY) $\approx 1.6 \times 10^{-5} \mathrm{~s}^{-1}$ can be estimated which lies in the order of simulated amplitudes $\left(\delta(\right.$ MM5DRY $\left.) \approx 3.3 \times 10^{-5} \mathrm{~s}^{-1}\right)$.

A similar investigation was done for the MM5WET run (Fig. 3b). It is obvious that the overall divergences have been amplified. The intensity of moist convection has been quantified with the latent heat release $Q_{*}$. Three events exceeding $Q_{*}=0.5 \mathrm{Kh}^{-1}$ are found at $s \approx 760,1150$ and $1600 \mathrm{~km}$. The most intense event with

$Q_{*}(\mathrm{MM} 5 \mathrm{WET}) \approx 1.3 \mathrm{~K} \mathrm{~h}^{-1}$ seems to be in positive interference with $\mathrm{J} 3$, as discussed with Fig. 2f. An estimate of the convection-generated divergence can be obtained as follows: The latent heating induces an upwind $\left(w_{*}\right)$ over a vertical temperature gradient

$\frac{\partial \Theta_{0}}{\partial z} \propto N^{2} \frac{\Theta_{0}}{g} \approx 3.7 \mathrm{Kkm}^{-1}$

which gives rise to convergence/divergence over the height of the convection cell of $H_{*}$.

An estimate of

Impact of

inertia-gravity waves

on wind and

precipitation

C. Zülicke and D. Peters

Title Page

Abstract

Introduction

Conclusions

References

Tables

Figures

14

$\triangleleft$

Back

Close

$\delta_{*}($ con $) \propto \frac{2 Q_{*}}{H_{*}\left(\partial T_{0} / \partial z\right)} \approx 3.3 \times 10^{-5} \mathrm{~s}^{-1}(\mathrm{MM} 5 \mathrm{WET})$

Printer-friendly Version

Interactive Discussion 
is found with the background temperature $\Theta_{0}=250 \mathrm{~K}$, gravitational acceleration $g=9.8 \mathrm{~m} \mathrm{~s}^{-2}$ and $H_{*}=6 \mathrm{~km}$. The imbalances in the upper tropospheric jet exit region appear to be slightly increased $\left(u_{*}\right.$ (jet, MM5WET) $\left.\approx 3.9 \mathrm{~m} \mathrm{~s}^{-1}\right)$ and give rise to jet-generated imbalances in the order of $\delta_{*}$ (jet, MM5WET) $\approx 1.8 \times 10^{-5} \mathrm{~s}^{-1}$. Hence, to5 gether with the convection-generated divergences $\delta_{*}\left(\right.$ MM5WET) $\approx 5.1 \times 10^{-5} \mathrm{~s}^{-1}$ can be expected as an highest value. Indeed, in the troposphere the simulated divergence shows values up to $\delta(\mathrm{MM} 5 \mathrm{WET}) \approx 6.4 \times 10^{-5} \mathrm{~s}^{-1}$ which is in the order of this estimate.

The initiation of convection by jet-generated IGWs is discussed next. As in Fig. $2 f$, the three jet-generated IGWs J4, J3 and J2 (indicated with solid lines) reach the surface 10 the dry run (Fig. 3a) at $s \approx 250,500$ and $1500 \mathrm{~km}$. Again, two V-shaped patterns can be found (at $s \approx 1750$ and $2000 \mathrm{~km}$ ). Slightly upstream of these positions the stronger convection events are found.

The jet-generated waves have some impact on the stratification, which is displayed in Fig. $3 c$ for the MM5DRY run. Near the surface, regions of negative vertical gradients 15 of potential temperature $(\partial \Theta / \partial z<0)$ can be found between $s=0-500,700-1150$ and at about $1350 \mathrm{~km}$ (indicated with I1, I2 and I3), where dry convection may set on. A region of decreased stability $\left(\partial \Theta / \partial z<3 \mathrm{~K} \mathrm{~km}^{-1}\right)$ at a height of $z=3 \mathrm{~km}$ can also be found between $s=1050-1550 \mathrm{~km}$. Using polarization relations it can be shown, that IGWs with a divergence of $\delta^{\prime}(\mathrm{MM} 5 \mathrm{DRY})=3.3 \times 10^{-5} \mathrm{~s}^{-1}$ are associated with temperature fluctua20 tions of

$T^{\prime} \propto T_{0} \delta^{\prime} \frac{N^{2}}{\omega_{i} k_{z} g} \approx 0.13 \mathrm{~K}(\mathrm{MM} 5 \mathrm{DRY})$

Corresponding vertical temperature gradients are of the order of

$\frac{\partial T^{\prime}}{\partial z} \propto k_{z} T^{\prime} \approx 0.50 \mathrm{Kkm}^{-1}(\mathrm{MM} 5 \mathrm{DRY})$

This is still smaller than the simulated variations of about $\pm 1.0 \mathrm{~K} \mathrm{~km}^{-1}$.

25 Another mechanism would be the excitation of convection lifting the saturated air parcel above the condensation level. Corresponding patterns of vertical velocity are 15886

\section{Impact of}

inertia-gravity waves

on wind and

precipitation

C. Zülicke and D. Peters

Title Page

Abstract

Conclusions

Tables

Figures

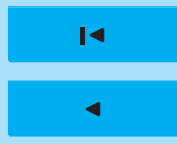

$\rightarrow 1$

Back

Close

Printer-friendly Version

Interactive Discussion

EGU 
shown in Fig. 3d with four phases of surface near upwind indicated with U1, U2, U3 and U4. On the large scale, the air is lifted due to the propagation of a cold front. Near the surface upwind regions are found at $s=350-450 \mathrm{~km}, 1050-1450$ and 1550$2150 \mathrm{~km}$ which could be the result of large-scale air mass lifting and superimposed jet5 and front-generated IGW patterns. Vertical velocity fluctuations associated with the IGW can be estimated as

$w^{\prime} \propto \frac{\delta^{\prime}}{k_{z}} \approx 1.9 \mathrm{~cm} \mathrm{~s}^{-1}(\mathrm{MM} 5 \mathrm{DRY})$

This is well in the order of the upwind patterns which are well-aligned to the positive divergences indicated with $\mathrm{J} 2, \mathrm{~J} 3$ and $\mathrm{J} 4$.

\subsection{Validation of surface wind pulsations}

In this section, the MM5 simulations are validated against observations of the $10 \mathrm{~m}$ wind speed $\left(u_{h, 10}\right)$ at Warnemünde (WMD).

Inspection of the time series of MM5 (Fig. 4a) shows a very strong surface wind pulse during the passage of a cold front at 18:00 UTC 17 December 1999 (labeled W2). The 15 peak value for the wind of $u_{h, 10}(\mathrm{WMD}, \mathrm{MM} 5)=20 \mathrm{~m} \mathrm{~s}^{-1}$ coincides with the arrival of an IGW. Belonging to this event a velocity fluctuation of $u_{h}{ }^{\prime}(\mathrm{WMD}, \mathrm{MM5})=3-4 \mathrm{~m} \mathrm{~s}^{-1}$ can be estimated from the peak-to-peak difference. This number well corresponds to the maximum divergence $\delta^{\prime}(\mathrm{MM} 5)=8 \times 10^{-5} \mathrm{~s}^{-1}$ from the high-resolution run (Fig. 2c, d) as may be verified with the relation

$20 \quad u_{h}^{\prime} \propto \frac{\delta^{\prime}}{k_{h}} \approx 2.8 \mathrm{~m} \mathrm{~s}^{-1}(\mathrm{MM} 5)$

Beside the strong peak W2 four weaker fluctuations may be found in the $3 \mathrm{~h}$ smoothed data: at 01:00 UTC 17 December (W1), 05:00 UTC 18 December (W3), 00:00 and 07:00 UTC 19 December 1999 (W4 and W5).

\section{ACPD}

7, 15873-15909, 2007

\section{Impact of}

inertia-gravity waves

on wind and

precipitation

C. Zülicke and D. Peters

Title Page

Abstract

Introduction

Conclusions

Tables

References

Figures

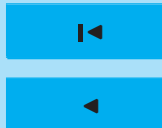

4

Back

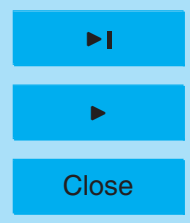

Full Screen / Esc

Printer-friendly Version

Interactive Discussion 
A similar time series appears in the MESAN data (Fig. 4b). While the W2 event appears with nearly the same amplitude and time, the amplitude and times for W3 and W4 differ slightly, and W5 comes up at the same time as in the MM5 time series. The MESAN data do not contain the first MM5 wind event (W1).

$5 \quad$ The observed wind speed time series from DWDMI data set is shown in Fig. 3c. It shows a sequence of wind pulses (W2, W3 and W4). The first wind pulse of DWDMI is contained in both MM5 and MESAN, but with smaller amplitude. The timing of the DWDMI wind pulses is the same as in MESAN. Keeping in mind, that an exact correspondence in time and space between local observation and modeled/assimilated

10 data cannot be expected, the time series of Kap Arkona (ARK, $54.7^{\circ} \mathrm{N}, 13.4^{\circ} \mathrm{E}$ ) is shown in Fig. 4d). For this DWDMI position, the correspondence to MM5 time series for Warnemünde is nearly perfect. This concerns the timing of the pulses and in particular the amplitude of W1.

\subsection{Correspondence to radar- and satellite-derived patterns}

In this section patterns of remotely sensed fields of high spatial and temporal resolution are analyzed for IGW structures.

Patterns of radar reflectivity $(Z)$ from the BALTRAD data set are shown in Fig. $5 \mathrm{a}$ and b. Strong signals are found at about 12:00 UTC 17 December 1999 (labeled with P2' like quasi-precipitation event number 2), which show up in the map as a 20 double-structure. This well compares with the precipitable water in the MM5 simulation (Fig. 2a). Two isolated signals are found at about 12:00 UTC 18 December and about 11:00 UTC 19 December 1999 (labeled with P3' and P5').

A similar pattern can be identified in the reflectivity classes from DWDPI composites (Fig. 5c, d). The P2' event is the strongest, while the evidence for events $P 3^{\prime}$ and $P 5^{\prime}$ 25 is supported with radar signals extending over several hours. The DWDPI reflectivity map again shows the double-structure for $\mathrm{P} 2$ '.

From the GFZGPS data a time series of height-integrated water vapor $\left(W_{v}=\int d z q_{v}\right)$ was constructed for Warnemünde (Fig. 5e). According to the large-scale synoptic sit-

Impact of

inertia-gravity waves

on wind and

precipitation

C. Zülicke and D. Peters

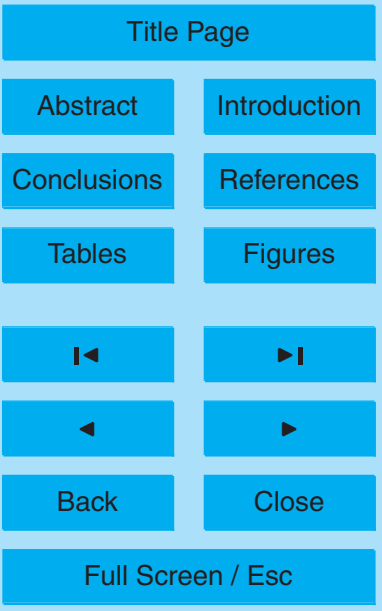

Printer-friendly Version

Interactive Discussion 
uation, subtropical moist air was substituting cold polar air in the two situations: first between 06:00 UTC and 18:00 UTC 17 December 1999 and second low-EPV between 06:00 UTC 18 and 00:00 UTC 19 December 1999. While these air mass properties are dominating the GFZGPS-WPV signal, only small fluctuations could be related to

5 IGWs. Two little peaks during the first phase (at 07:30 and 15:30 UTC 17 December 1999) could possibly related to the double-peak-structure mentioned with the W2 and P2' events. During the second moist-air-phase we find two modulations peaking at 10:30 UTC and 19:30 UTC 18 December 1999 - possibly effects of W3 and W4. Little coherence of the two peaks around $\mathrm{P5}^{\prime}$ (07:30 and 14:30 UTC 19 December 1999) is 10 found with DWDMI wind speed.

\subsection{Validation of precipitation events}

Precipitation is presented as an accumulated quantity in maps for 18:00 UTC 17 December 1999 (Fig. 6) and time series for Warnemünde (Fig. 7).

The maps provide 100-km-averaged data accumulated over at least $1 \mathrm{~h}$ in order to allow for sufficient resolution of the relevant scale. In the data from MM5, MESAN, ELDAS and BALTRAD the double-front structure of P2 can be identified. The most extended dataset (ELDAS, Fig. 6c) also includes another east-west-oriented band west of England (at about $52^{\circ} \mathrm{N}$ ). The limited dataset of DWDMI (Fig. 6a) confirms the occurrence of precipitation in the north-western part of Germany.

20 A review of the Warnemünde time series of the three-hourly accumulated precipitation (Fig. 7) shows coherently most of precipitation during the P2 event. Only in the MESAN dataset (Fig. 7b) even the double-peak structure can be diagnosed. While precipitation during event P3 could be found in MM5 (Fig. 7a), MESAN (Fig. 7b) and ELDAS (Fig. 7c), it weakly or not at all appeared in the radar-derived BALTRAD (Fig. 7d) 25 and rain-gauge DWDMI (Fig. 7e). Event P5 in MM5 (Fig. 7a) is only coherent with BALTRAD-derived rainfall (Fig. 7d), while the MM5-P1 is only related to an insignificant signal in BALTRAD (at about 03:00 UTC 17 December 1999).

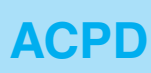

7, 15873-15909, 2007

\section{Impact of}

inertia-gravity waves

on wind and

precipitation

C. Zülicke and D. Peters

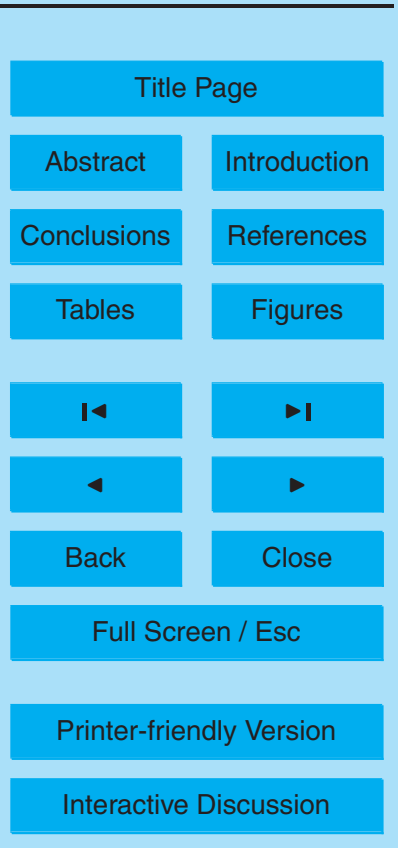




\subsection{Wind and precipitation in the Gotland Basin}

After the validation of available data at a land station, the surface weather patterns for a position in the Central Baltic proper are presented. The Gotland Basin $\left(56.5^{\circ} \mathrm{N}\right.$, $20.0^{\circ} \mathrm{E}$ ) is chosen for this analysis because clear IGW signals are expected without

5 influence of orography. Different datasets have been compiled for the Gotland Basin and are presented in Fig. 8.

The Gotland Basin time series of the wind from MM5 (Fig. 8a) and MESAN (Fig. 8b) both show 5 peaks in the wind speed. The strongest peak (W2) is nearly identical with respect to timing (difference is less than $3 \mathrm{~h}$ ) and magnitude (difference less than

$101 \mathrm{~m} \mathrm{~s}^{-1}$ ). No evidence for a double-front structure for P2 could be found which is corresponding to Fig. 6 . The following peaks (W3, W4 and W5) are appearing in MM5 about $6 \mathrm{~h}$ later than in MESAN. A similar time delay can be diagnosed for the precipitation which is shown in Fig. 8(a, MM5) and (b, MESAN). The precipitation magnitude of the strongest precipitation event (P2) is in MESAN roughly half as intense as in MM5. Precipitation from the ELDAS (Fig. 8e) and BALTRAD (Fig. 8f) support the value for P2 provided by MM5. The other peaks (P1, P3, P4 and P5) appear with varying intensity in the different datasets. The MM5 precipitation events (Fig. 8c) appear at nearly the same time as the MM5 wind pulses (Fig. 8a), while the precipitation in the other datasets (MESAN in Fig. 8d, ELDAS in Fig. 8e and BALTRAD in Fig. 8f) are synchronous with the MESAN wind pulses (Fig. 8b). The time difference, however, is about $6 \mathrm{~h}$ which is just twice the precipitation accumulation time. Hence, the latter observation is more an indication than a statement.

\section{Impact of}

inertia-gravity waves

on wind and

precipitation

C. Zülicke and D. Peters

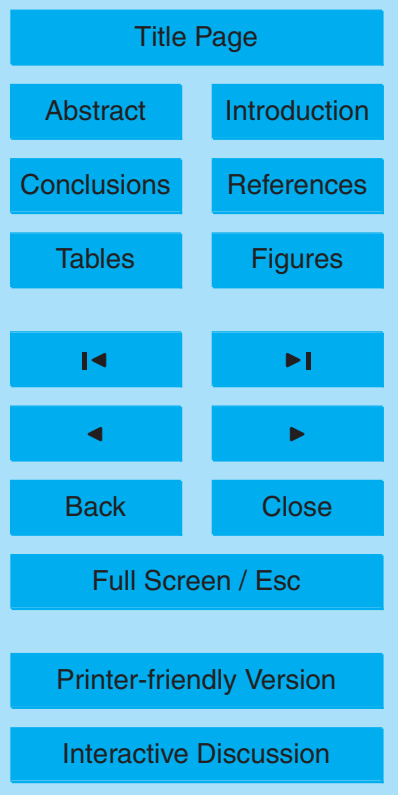




\section{Discussion}

\subsection{Numerical simulation of IGWs}

IGWs were generated through internal dynamics of the MM5 model. It has been forced through the boundaries only, which was coarse-grained an on a horizontal grid of

$5144 \mathrm{~km}$ and $12 \mathrm{~h}$. For the near-realistic simulation of IGW features it was necessary to run MM5 with sufficient resolution. Two aspects are important: (i) the dynamics should allow for unbalanced (ageostrophic) motion and (ii) the model-internal diffusion should not damp the IGWs. If a mesoscale wave of $200 \mathrm{~km}$ wavelength shall be simulated properly, the model should be run with a horizontal resolution of about $8 \mathrm{~km}$ and 10 a vertical resolution of about $100 \mathrm{~m}$ in both troposphere and stratosphere (Zülicke and Peters, 2006). The effective resolution in the troposphere can be estimated with

$\Delta s_{\text {eff }}=\max \left(\Delta s, \frac{N}{f} \Delta z\right)$

and rounds up to $\Delta \mathrm{s}_{\text {eff }}(\mathrm{MM} 5)=8.6 \mathrm{~km}$. Such simulations are computer time intensive because they require the integration of $300^{3}$ grid points. The resolution of the models 15 reported for the REMO model by Jacob et al. (2001) was about $\Delta s(\mathrm{REMO})>18.5 \mathrm{~km}$ and $\Delta z(\mathrm{REMO})>1 \mathrm{~km}$ in the upper troposphere. The corresponding effective resolution was $\Delta s_{\text {eff }}(\mathrm{REMO}) \approx 86 \mathrm{~km}$ which makes it difficult to simulate IGWs properly. However, models with a resolution insufficient to generate IGWs by internal dynamics can be forced to show IGWs if observations are assimilated. This was the case with ELDAS and MESAN datasets. ELDAS uses ECMWF analyses with an effective resolution of $\Delta s_{\text {eff }}($ ERA40 $)=86 \mathrm{~km}$. Similar estimates hold for the HIRLAM background data used for MESAN with an effective resolution $\Delta s_{\text {eff }}($ HIRLAM $) \approx 47 \mathrm{~km}$.

The high-resolution MM5 model generated IGWs with a horizontal wavelength of $\lambda_{h}(\mathrm{MM} 5) \approx 220 \mathrm{~km}$ and a vertical wavelength of $\lambda_{z}(\mathrm{MM} 5) \approx 3.5 \mathrm{~km}$. The related intrin25 sic period qualifies them as sub-inertial. They correspond to those IGWs found in the statistical analysis for the position of Kühlungsborn (Zülicke and Peters, 2006).

Impact of

inertia-gravity waves on wind and precipitation

C. Zülicke and D. Peters

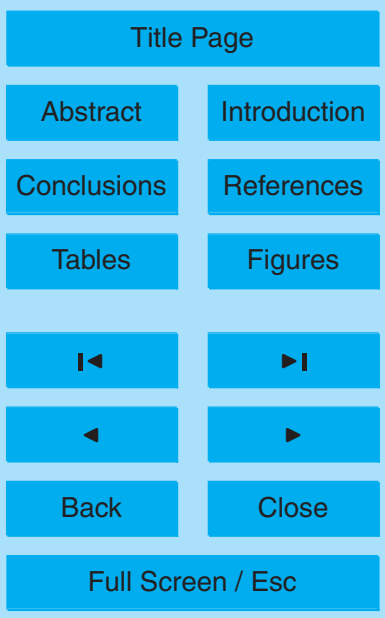

Printer-friendly Version

Interactive Discussion 
The related apparent period of about $9 \mathrm{~h}$ well corresponds to the peak-to-peak-time of about $12 \mathrm{~h}$ found in the wind observations (Fig. 4c). A comparison of the wind time series at Warnemünde (Fig. 4a) and the Gotland Basin (Fig. 8a) suggests a time delay of about $6 \mathrm{~h}$. This can be explained with the propagation of the IGW with an apparent 5 phase speed in wave direction of $c_{a}=u_{\|}+\lambda_{\|} / \tau_{i} \approx-5.7 \mathrm{~m} \mathrm{~s}^{-1}$. While the distance between Warnemünde and the Gotland Basin is $\delta s \approx 564 \mathrm{~km}$, its projection onto the wave direction is $\delta s_{\|}=\delta s \cos \left(75^{\circ}\right) \approx 145 \mathrm{~km}$. Hence, the IGW needs a time of $\delta t=\delta s_{\|} / c_{a} \sim 7.1 \mathrm{~h}$ to overcome this distance.

\subsection{Interaction of jet-generated IGWs and convection}

10 The importance of upper tropospheric jet-generated IGWs in the present meteorological situation was shown. This come apparent from the high-resolution (Fig. 2d) and the low-resolution runs (Fig. 3a, b) where backward inclined phaselines were found above the jet and forward inclined phases below. From the analysis of time series it was diagnosed, that the phase propagation was downward above the jet and, hence, the energy propagation upward. The opposite holds for the region below the jet with upward phase and downward energy. A significant part of IGW amplitudes could be attributed to imbalances in the exit region of the jet.

These relatively large and shallow IGWs are modifying the stratification and upwind condition and, thus, may initiate convection. Although this "triggering" appeared to be weak in the medium-resolution MM5DRY run, we expect it to be clearer with higher resolution. The divergence structures in the MM5 run are about two times stronger than in MM5DRY. Hence, the related stratification varies with $\partial T^{\prime} / \partial z(\mathrm{MM} 5) \approx 1.1 \mathrm{~K} \mathrm{~km}^{-1}$ (using Eqs. 7 and 8) which is in the order of diagnosed variations (Fig. 3c) and half of the background gradient (Eq. 5). The vertical velocity fluctuations can be estimated

25 as $w^{\prime}(\mathrm{MM} 5) \approx 4.6 \mathrm{~cm} \mathrm{~s}^{-1}$ using Eq. (9). They too come in the range of the large-scale lifting motion (Fig. 3d).

The convection events were embedded into IGW patterns of convergence/divergence and related up/downdrafts. According to the conceptual model of

\section{Impact of}

inertia-gravity waves

on wind and

precipitation

C. Zülicke and D. Peters

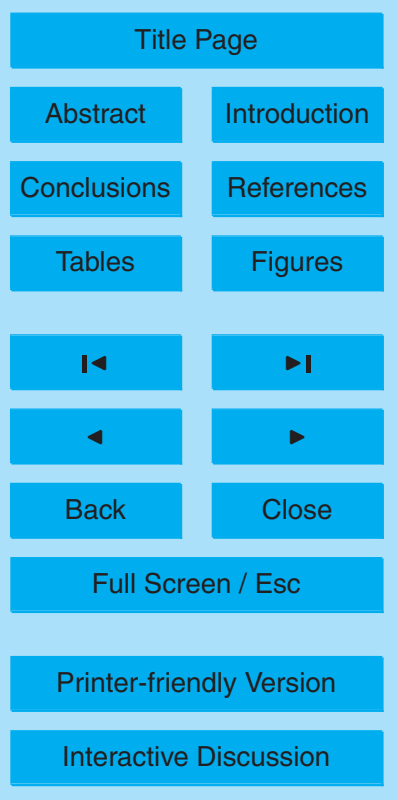

EGU 
Koch and Golus (1988) convective rain bands are found above surface convergence or slightly shifted upstream. The hypothesis is that saturated air can be lifted by IGWs up to their condensation level. Once induced, condensation develops to deep convection. This way, upper tropospheric jet-generated IGWs may favor certain 5 regions for convection at characteristic scales of some hundred kilometers. Note, that the development of individual convection cells takes place at scales of less then ten kilometers. This part of the dynamics is not resolved but parameterized in the current study. The resulting pattern consists of differently aligned IGW structures; however, the characteristic scale of jet-generated IGWs can be recovered. Hence, the

10 IGWs communicate information on scales, which are defined at the tropopause level. Associated convection patterns add evidence to the impact of upper tropospheric jet-generated IGWs on the boundary layer dynamics.

Once initiated, deep convection forces new IGWs. The latent heat release was identified as the relevant energy source (see Eq. 6). It leads to an amplification of the 15 divergence patterns in the lower troposphere. Another effect is the increase of imbalance of the jet exit in the tropopause by about $11 \%$. Here the horizontal diffluence of the jet combined with the vertical divergence at top of the convection towers. Comparing the magnitude of divergence in the lower stratosphere we find an increase by about $100 \%$ similar as in (Zülicke and Peters, 2006). This is the result of upward propagating convection-generated IGWs rather than large-scale effects and demonstrates the process of amplification of lower-stratospheric IGW activity by deep convection.

\subsection{Observations of IGW effects}

IGW signatures have been detected in wind speed time series. They are characterized by a strong peak (W2) of about $22 \mathrm{~m} \mathrm{~s}^{-1}$ accompanied with by four pulsations (W1, ${ }_{25}$ W3, W4 and W5). These features were present in MM5 simulations (Fig. 4a) and the assimilated dataset MESAN (Fig. 4b) at the position of Warnemünde. The DWDMI observation at this site (Fig. 4c) showed strong evidence for wind pulsations. No other station showed such an exceptional sinusoidal sequence (W2, W3 and W4) which

\section{Impact of}

inertia-gravity waves

on wind and

precipitation

C. Zülicke and D. Peters

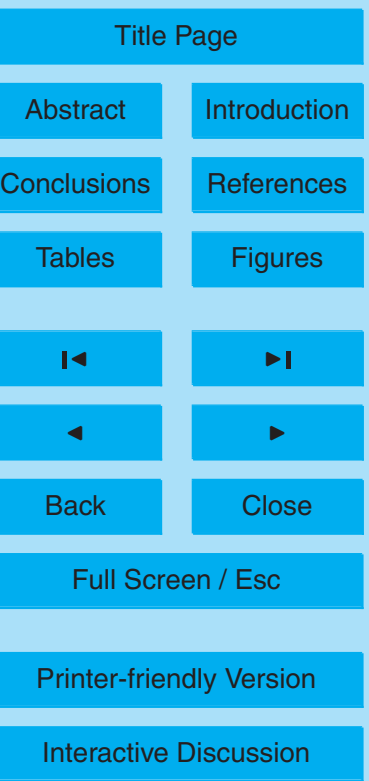


can be considered as a "textbook example" for IGWs. A similar time series with even larger winds is found for Kap Arkona (Fig. 4d). This station at the North tip of Rugenia Island is about $100 \mathrm{~km}$ East-North-East of Warnemünde and can be considered as representative for the wind over the open Baltic Sea. The position of Warnemünde at

5 the East-West-aligned coast accounts for some of the wind reduction over land which reduced the W2 peak. Such a decrease in amplitude was also found in DWDMI for the station Greifswald $\left(54.1^{\circ} \mathrm{N}, 13.4^{\circ} \mathrm{E}\right.$, not shown). The coherence of MM5 and MESAN wind speed as found at Warnemünde can be confirmed for the Gotland Basin (Fig. 8a, b).

10 A direct comparison of the wind speed from MM5 simulations for Warnemünde and DWDMI observations for Kap Arkona shows that the wind maximum was reproduced exactly in time with an uncertainty of $\pm 1 \mathrm{~m} \mathrm{~s}^{-1}$. Mostly, this quantity is overestimated by mesoscale models (Jacob et al., 2001). In the present study, the high-resolution MM5 model performed satisfactory. IGW structures were much clearer expressed at 15 a validation site in the Eastern Gotland Sea, both in MM5 simulations and MESAN analyses. The variability in both datasets was comparable although the amplitudes were slightly smaller in MESAN.

IGW patterns were also detected in radar-derived reflectivity patterns. The doublefront structure of the quasi-precipitation event P2' in BALTRAD (Fig. 5b) and DWDPI 20 (Fig. 5d) is corresponding to the MM5 simulated integrated precipitable mass (Fig. 2a). In the cross section (Fig. 2b) both stripes can be found at the position of $s=1550$ and $1750 \mathrm{~km}$ suggesting a distance of about $200 \mathrm{~km}$. This number is near the estimated horizontal wavelength and suggests the split front is guided by IGWs. The split front for $\mathrm{P}^{\prime}$ is accompanied by weak variations in radar reflectivity (Fig. 5a, c). Two further 25 events $\left(\mathrm{P}^{\prime}\right.$ and $\mathrm{P}^{\prime}$ ) are found for Warnemünde in both BALTRAD and DWDPI. It is interesting to note, that only one single signal are contained in BALTRAD while scattered signals are in DWDPI. This is due to the fact that BALTRAD assimilates only the radar from Warnemünde while the DWDPI product is using overlapping signals from Rostock and Hamburg.

\section{Impact of}

inertia-gravity waves

on wind and

precipitation

C. Zülicke and D. Peters

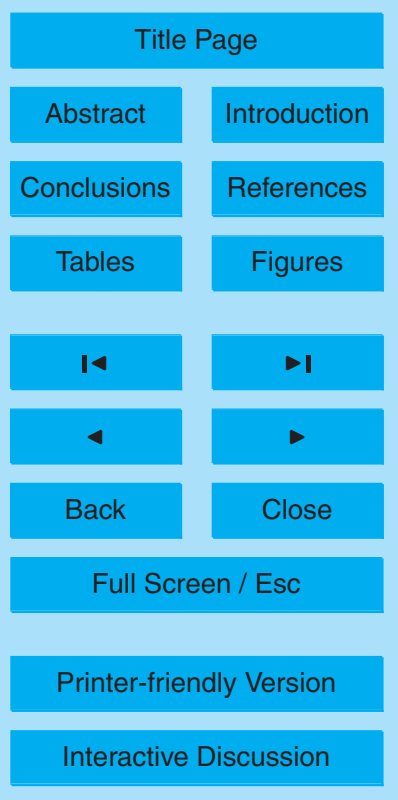

\section{4}


Some variations in the integrated water vapor from GFZGPS (Fig. 5e) could be related to the radar reflectivity of precipitable water. Most of the signal is related to large-scale changes in air mass. The two events with northerly polar air inflow after westerly import of subtropical air (around 00:00 UTC 18:00 and 12:00 UTC 19 Decem5 ber 1999) are the result of the two synoptic scale vorticity anomalies associated to the RWB event.

The validation of precipitation at Warnemünde with DWDMI data was relatively poor: Although the major event P2 was found in all datasets (Fig. 7), the occurrence of the other events (P1, P3, P4 and P5) was not coherently reflected. For this occasion, 10 MM5 overestimated the intensity of rainfall by about $100 \%$ while the MESAN, ELDAS and BALTRAD agreed reasonably. This is due to the adjustment of the Z-R-relation to available rain gauge observations. However, many reasons account for the disagreement between modeled and assimilated estimates: This is the representativity of a point measurement (DWDPI) against the coarse-grained and smoothed modeled 15 (MM5) and assimilated products (MESAN, ELDAS, BALTRAD). Another argument is the rain gauge measurement error due to sweep-in and sweep-out of rainwater in windy situations. Inspection of the modeled and assimilated datasets in the Gotland Basin shows a major precipitation event P2 (about $3 \mathrm{~mm}(3 \mathrm{~h})^{-1}$ ) in MM5 (Fig. 8c), ELDAS (Fig. 8e) and BALTRAD (Fig. 8f) while the signal in MESAN (Fig. 8c) was only half 20 (about $\left.1.5 \mathrm{~mm}(3 \mathrm{~h})^{-1}\right)$. The slight underestimation of precipitation by MESAN has also been found by (Rutgersson et al., 2001). The minor events (P1, P3 and P4) could be detected in all datasets while the evidence for P5 in BALTRAD is weak. The differences in timing between all the data are small (about $\pm 3 \mathrm{~h}$ ). The intensity of the minor precipitation events is varying - even the events exceeding $1.5 \mathrm{~mm}(3 \mathrm{~h})^{-1}$ are not appearing 25 homogeneously (P1 in MM5 and BALTRAD, P3 in MM5 and ELDAS). The most probable reason is the methodological difference in how the precipitation was estimated: while MM5 it is parameterized convection, in MESAN and ELDAS assimilated radar and gauges while gauge-calibrated radars were used. However the rain intensity was, its appearance was closely related to the IGW signatures in the mesoscale wind field.

\section{Impact of \\ inertia-gravity waves on wind and precipitation}

C. Zülicke and D. Peters

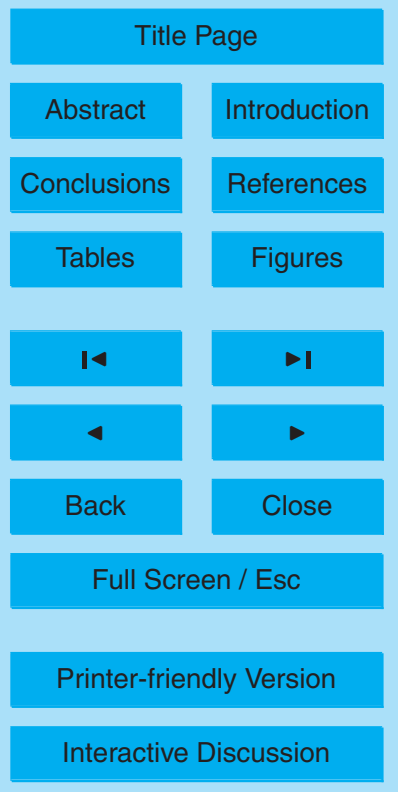




\subsection{Consequences for air-sea exchange}

The modeled mesoscale effects in the atmospheric boundary layer also have consequences for mesoscale ocean dynamics. As an example the input of turbulent kinetic energy into the ocean is discussed which scales like $u_{h}^{3}$. Adding a fluctuation of $53.5 \mathrm{~m} \mathrm{~s}^{-1}$ to a mean wind of $15 \mathrm{~m} \mathrm{~s}^{-1}$ an energy input of about $(18.5 / 15.0)^{3} \sim 188 \%$ with respect to the mean value is found. Although such an event is not lasting long, the ocean surface mixed layer may react during hours and mixes down with nearly double energy. Note, that related effects like entrainment and erosion of the thermocline would have not been correctly described using the mean wind over $6 \mathrm{~h}$ only.

\section{Summary and conclusion}

In a meteorological case study over Northern Europe from 17 to 19 December 1999 the impact of upper tropospheric jet-generated IGWs on the local wind and precipitation fields was documented. A schematic illustration of these processes is shown in Fig. 9. The IGWs are spontaneously radiated from the exit region of the upper tropospheric jet streak and propagate energy downward to the surface. In a downstream cross section such waves appear forward inclined. Near the surface they lead to wind pulsations and may trigger precipitation events. The interaction of jet-generated and convectiongenerated IGWs leads to a complex pattern in the lower troposphere. It intensifies at sub-synoptic scales which are defined by the IGW generation process in the upper tropospheric jet. In these preconditioned regions shorter-scale IGWs are convectively generated which propagate upward into the stratosphere. Hence, the convection in the lower troposphere serves as an amplifier of IGW activity.

For a mutual inter-validation of simulations with observations we compared data from several sources. The successful simulation of jet- and convectively generated IGWs requires a high vertical and horizontal model resolution. The observed wind fluctuations of about $3.5 \mathrm{~m} \mathrm{~s}^{-1}$ (Fig. 4c) could be related to the intensity of simulated IGWs (see

\section{Impact of}

inertia-gravity waves

on wind and

precipitation

C. Zülicke and D. Peters

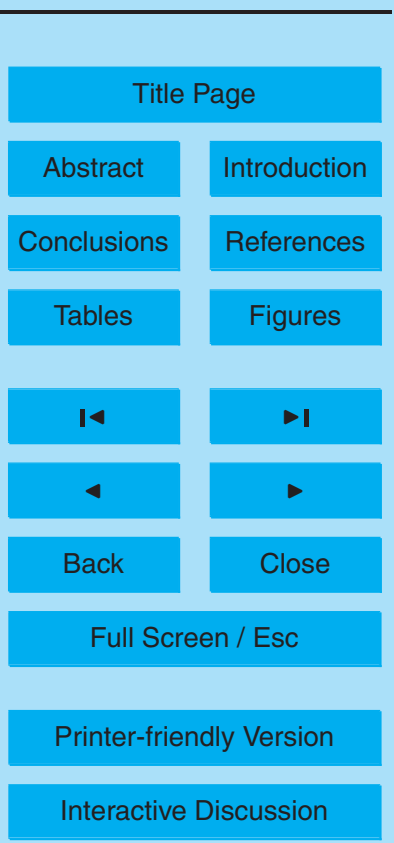


Eq. 10). The space and time scales of convection and precipitation systems were related to those of jet-generated IGWs. These processes were simulated by MM5 with sufficient accuracy which confirms the proper setup of the mesoscale model. The validation with DWD and BALTRAD observations suggests that surface wind pulsations 5 and precipitation events in this case study are IGW features. Confidence can also be assigned to the mesoscale MESAN and ELDAS assimilation products, where similar scales have been identified. Hence, MESAN data could be used as a forcing function for mesoscale ocean circulation models including scales which are not resolved in ECANA, for example.

10 The MM5 simulations were used in this process study to diagnose the energetic sources for the IGWs: while the wind speed tendency sets the amplitude of jetgenerated IGWs, the latent heat release accounts for the intensity of convectiongenerated IGWs. These forcing parameters could be taken as a base for parameterizations for a realistic modeling of IGW activity in the mid-latitudes, in particular 15 during RWB. The statistical evaluation of this hypothesis will be subject of future studies. Based on the analysis of available data, situations should be searched, which are linked to strong upper tropospheric jets and fast northward progression of subtropical warm moist air. Certainly, such weather patterns are present in poleward RWB which appear often over northern Europe during winter. The improvement of statistics and understanding of mesoscale dynamics represents a basic aspect of air-sea exchange and has implications on regional energy and water budget studies. It is also relevant for IGWs in upper levels of the atmosphere.

Acknowledgements. The funding of the work through the DFG project PIGW (Precipitation and Inertia-gravity waves; contract PE 474/4-1/2) with logistic support from the DFG priority pro25 gram QPF (Quantitative Precipitation Forecast, SPP 1167) is gratefully acknowledged. We are also thankful to the user support groups at DKRZ Hamburg (HLRE project 48) and NCAR Boulder for keeping MM5 running. ECMWF Reading and DWD Offenbach have kindly provided the ECANA data. Special thanks for data provision and assistance in processing goes to: K. Boqvist (SMHI Norrkoeping) for MESAN, J. Wickert and G. Dick (GFZ Potsdam) for GFZGPS, 30 F. Rubel and P. Skomorowski (U Vienna) for ELDAS, D. Michelson and G. Haase (SMHI Nor-

\section{Impact of \\ inertia-gravity waves on wind and precipitation}

C. Zülicke and D. Peters

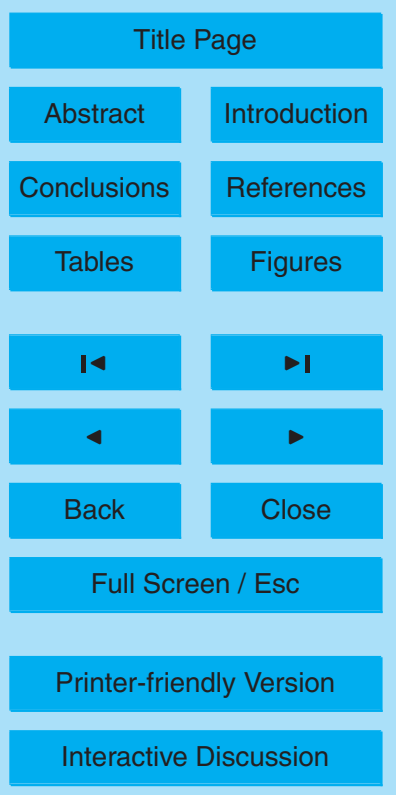

EGU 
rkoeping) for BALTRAD and C. Koziar (DWD Offenbach) for DWDPI and DWDMI. Fruitful discussions with G. Schmitz and A. Gabriel (IAP Kühlungsborn), R. Feistel (IO Warnemünde), C. Nappo (NOAA Oak Ridge) and K. Bumke (IfM-GEOMAR Kiel) helped to improve the paper.

\section{References}

5 Alexander, M. J. and Holton, J. R.: On the spectrum of vertically propagating gravity waves generated by a transient heat source, Atmos. Chem. Phys., 4, 923-932, 2004, http://www.atmos-chem-phys.net/4/923/2004/.

Bosart, L. F. and Cussen, J. P. J.: Gravity wave phenomena accompanying east coast cyclogenesis, Mon. Weather Rev., 101, 446-454, 1973.

10 Bosart, L. F., Bracken, W. E., and Seimon, A.: A study of cyclone mesoscale structure with emphasis on a large-amplitude inertia-gravity wave, Mon. Weather Rev., 126, 1497-1527, 1998.

Dudhia, J.: A non-hydrostatic version of the penn state-ncar mesoscale model: Validation tests and simulation of an atlantic cyclone and cold front, Mon. Weather Rev., 121, 1493-1513, 1993.

DWD: Composite products, World Wide Web, http://www.dwd.de/en/Technik/Datengewinnung/ Radarverbund/Komposit/Komposit.htm, 2006.

Fritts, D. and Alexander, M. J.: Gravity wave dynamics and effects in the middle atmosphere, Rev. Geophys., 41, doi:10.1029/2001RG000106, 2003.

Gendt, G., Dick, G., Reigber, C., Tomassini, M., Liu, Y., and Ramatschi, M.: Near real time gps water vapor monitoring for numerical weather prediction in Germany, J. Met. Soc. Jap., 82, 361-370, 2004.

Grell, G. A., Dudhia, J., and Stauffer, D. R.: A description of the fifth-generation penn state/ncar mesoscale model (mm5), Techn. Note (Nat. Cent. for Atmos. Res., Boulder, Colo.), 398, 122, 251995

Guest, F. M., Reeder, M. J., Marks, C. J., and Karoly, D. J.: Inertia-gravity waves observed in the lower stratosphere over macquarie island, J. Atmos. Sci., 57, 737-752, 2000.

Häggmark, L., Ivarsson, K.-I., Gollvik, S., and Olofsson, P.-O.: Mesan, an operational mesoscale analysis system, Tellus, 52A, 2-20, 2000.

Holton, J. R.: An introduction to dynamic meteorology, Academic Press, London, 1992.

\section{Impact of}

inertia-gravity waves

on wind and

precipitation

C. Zülicke and D. Peters

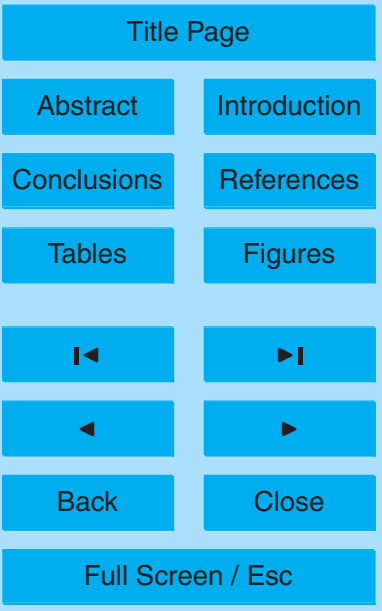

Printer-friendly Version

Interactive Discussion 
Jacob, D., van den Hurk, B. J. J. M., Andrae, U., Elgered, G., Fortelius, C., Graham, L. P., Jackson, S. D., Karstens, U., Köpken, C., Lindau, R., Podzun, R., Rockel, B., Rubel, F., Sass, B. H., Smith, R. N. B., and Yang, X.: A comprehensive model inter-comparison study investigating the water budget during the baltex-pidcap period, Meteorol. Atmos. Phys., 77, 19-43, 2001.

Kim, Y.-J., Eckermann, S. D., and Chun, H.-Y.: An overview of the past, present and future of gravity-wave drag parameterisation for numerical climate and weather prediction models, Atmos. Ocean, 41, 65-98, 2003.

Koch, S. E. and Golus, R. E.: A mesoscale gravity wave event observed during ccope. Part I: Multiscale statistical analysis of wave characteristics, Mon. Weather Rev., 116, 2527-2544, 1988.

Koistinen, J. and Michelson, D. B.: Baltex weather radar-based precipitation products and their accuracies, Boreal Env. Res., 7, 253-263, 2002.

Lane, T. P., Reeder, M. J., and Clark, T. L.: Numerical modeling of gravity wave generation by 15 deep tropical convection, J. Atmos. Sci., 58, 1249-1274, 2001.

Lane, T. P., Doyle, J. D., Plougonven, R., Shapiro, M. A., and Sharman, R. D.: Observations and numerical simulations of inertia-gravity waves and shearing instabilities in the vicinity of a jet stream, J. Atmos. Sci., 61, 2692-2706, 2004.

Michelson, D. B. and Koistinen, J.: Gauge-radar network adjustment for the baltic sea experiment, Phys. Chem. Earth, B15, 915-920, 2000.

O'Sullivan, D. and Dunkerton, T. J.: Generation of inertia-gravity waves in a simulated life cycle of a baroclinic instability, J. Atmos. Sci., 52, 3695-3716, 1995.

Peters, D. and Waugh, D. W.: Influence of barotropic shear on the poleward advection of uppertropospheric air, J. Atmos. Sci., 53, 3013-3031, 1996.

Peters, D., Hoffmann, P., and Alpers, M.: On the appearance of inertia-gravity waves on the north-easterly side of an anticyclone, Meteorol. Z., 12, 25-35, 2003.

Plougonven, R., Teitelbaum, H., and Zeitlin, V.: Inertia gravity wave generation by the tropospheric midlatitude jet as given by the fronts and atlantic strom track experiments radio soundings, J. Geophys. Res., 103, 4686, doi:10.1029/2003JD003535, 2003.

30 Reeder, M. J. and Griffiths, M.: Startospheric inertia-gravity waves generated in a numerical model of frontogenesis. li: Wave sources, generation mechanisms and momentum fluxes, Q. J. R. Meteorol. Soc., 122, 1175-1195, 1996.

Reigber, C., Gendt, G., and Wickert, J.: Gps atmosphären-sondierungs-project (gasp), GFZ

\section{Impact of \\ inertia-gravity waves \\ on wind and \\ precipitation}

C. Zülicke and D. Peters

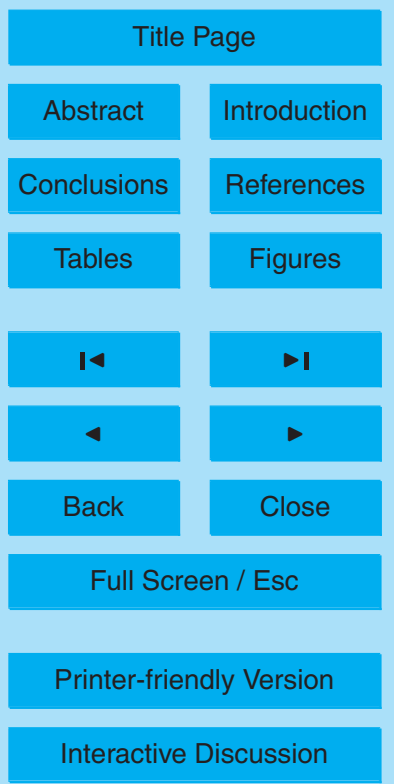

EGU 
STR (Geoforschungszentrum Scientific Technical Report), 04/02, (ISSN 1610-0956), 2002.

Rubel, F. and Hantel, M.: Baltex 1/6-degree daily precipitation climatology 1996-1998, Meteorol. Atmos. Phys., 77, 155-166, 2001.

Rubel, F.: A new european precipitation dataset for nwp model verification and data assimulation studies, in: Research activities in atmospheric and oceanic modelling, edited by: Cote, J., WMO/TD, 2004.

Rutgersson, A., Bumke, K., Clemens, M., Foltescu, V., Lindau, R., Michelson, D., and Omstedt, A.: Precipitation estimates over the baltic sea: Present state of the art, Nord. Hydrol., 32, 285-314, 2001.

10 Thomas, L., Worthington, R. M., and McDonald, A. J.: Inertia-gravity waves in the troposphere and lower stratosphere associated with a jet stream exit region, Ann. Geophys., 17, 115-121, 1999, http://www.ann-geophys. net/17/115/1999/.

Uccellini, L. W.: A case study if apparent gravity wave initiation of severe convective storms, Mon. Weather Rev., 103, 497-513, 1975.

Uccellini, L. W. and Koch, S. E.: The synoptic setting and possible energy sources for mesoscale wave disturbances, Mon. Weather Rev., 115, 721-729, 1987.

Zhang, F., Koch, S. E., Davis, C. A., and Kaplan, M. L.: A survey of unbalanced flow diagnostics and their application, Adv. Atmos. Sci., 17, 165-183, 2000.

Zhang, F.: Generation of mesoscale gravity waves in upper-tropospheric jet-front systems, J. 20 Atmos. Sci., 61, 440-457, 2004.

Zülicke, C. and Peters, D.: Simulation of inertia-gravity waves in a poleward breaking rossby wave, J. Atmos. Sci., 63, 3253-3276, doi:10.1175/JAS3805.1, 2006.

Zülicke, C. and Peters, D.: Parameterization of strong stratospheric inertia-gravity waves forced by poleward breaking rossby waves, Mon. Weather Rev., in press, 2007.

\section{Impact of \\ inertia-gravity waves \\ on wind and \\ precipitation}

C. Zülicke and D. Peters

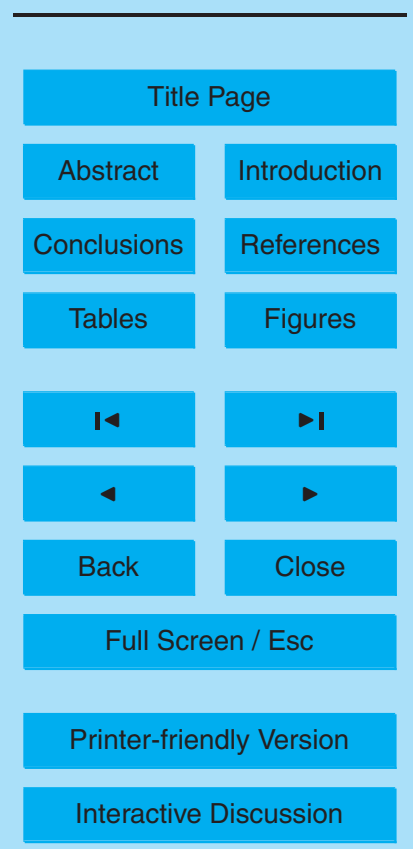


(a)

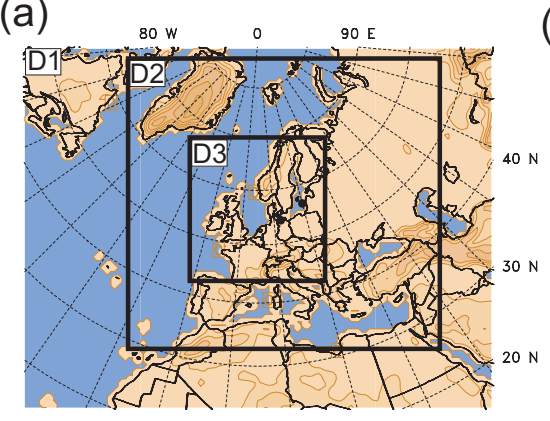

(b)

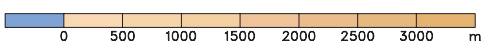

(c)

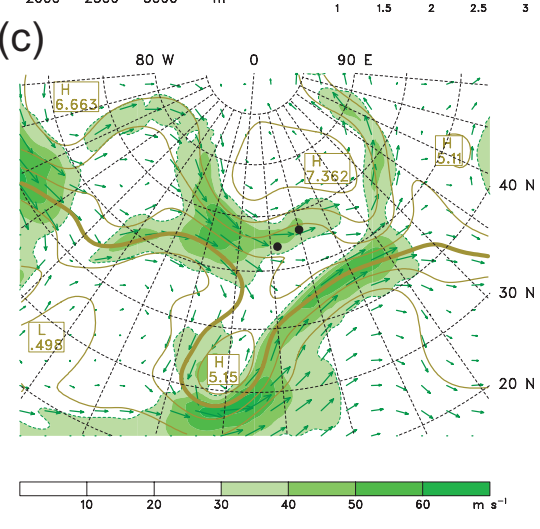

Fig. 1. Meteorological situation for 18:00 UTC 17 December 1999 from ECANA data. (a) Target region with nested MM5 model domains and terrain height (filled contours each $500 \mathrm{~m}$ ), (b) specific humidity at $500 \mathrm{hPa}$ (filled dotted contours, $q_{v}=1.0,1.5,2.0, \ldots \mathrm{g} \mathrm{kg}^{-1}$ ) and sea level pressure (solid contours, $\Delta p_{\mathrm{slv}}=10 \mathrm{hPa}$ ), (c) $330 \mathrm{~K}$ map with the wind (arrows and isotachs, filled dotted contours, $u_{h}=30,40,50, \ldots \mathrm{m} \mathrm{s}^{-1}$ ) together with the 100-km-smoothed Ertel potential vorticity (solid contours, $\triangle E P V=1 \mathrm{PVU}, 3 \mathrm{PVU}$ thick). Dots indicate the positions of Warnemünde $\left(54.2^{\circ} \mathrm{N}, 12.1^{\circ} \mathrm{E}\right)$ and the Gotland Basin $\left(56.5^{\circ} \mathrm{N}, 20.0^{\circ} \mathrm{E}\right)$.

\section{ACPD}

7, 15873-15909, 2007

\section{Impact of \\ inertia-gravity waves \\ on wind and \\ precipitation}

C. Zülicke and D. Peters

\section{Title Page}

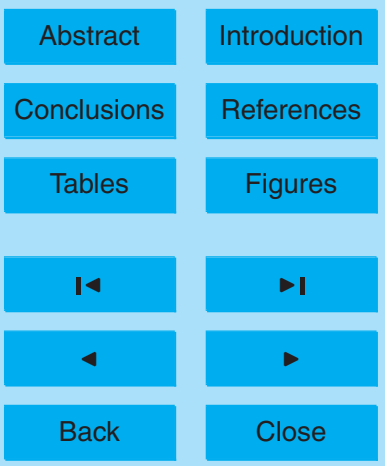

Full Screen / Esc

Printer-friendly Version

Interactive Discussion 
(a)

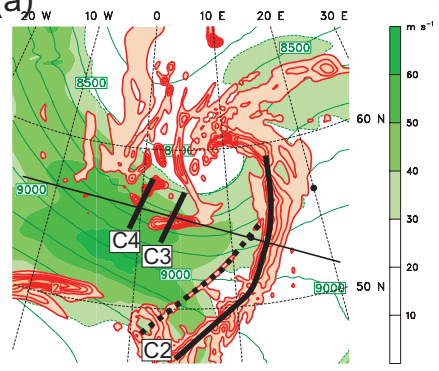

(c)

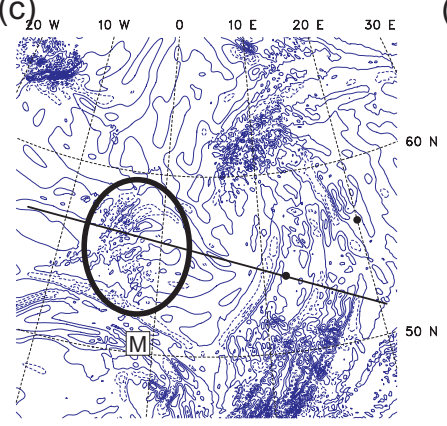

(e)

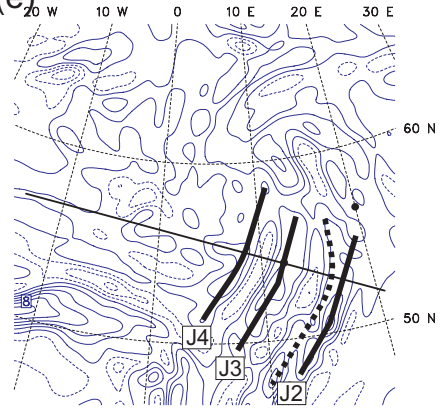

(b)

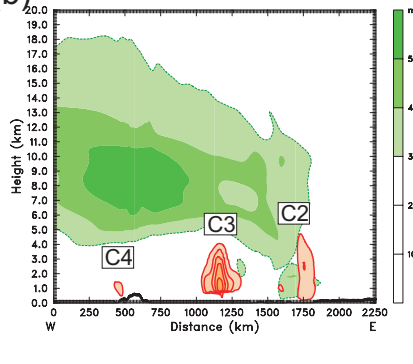

(d)

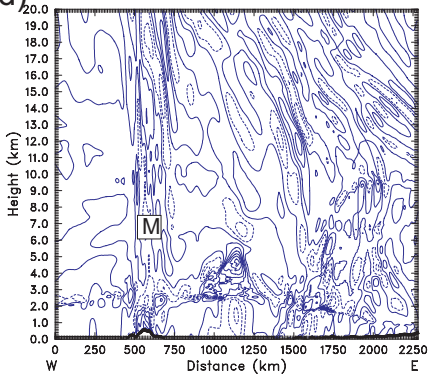

(f)

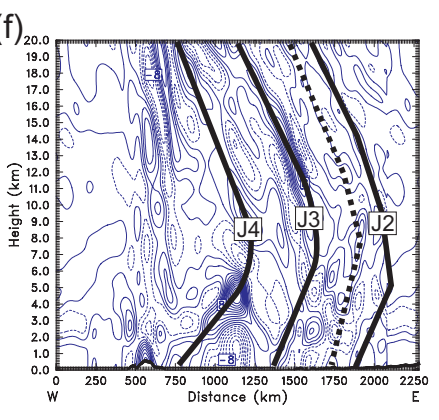

Fig. 2. MM5 modeled IGW patterns for 18:00 UTC 17 December 1999. (a, c, e) $300 \mathrm{hPa}$ maps and (b, d, f) a vertical cross section through Warnemünde. wind speed (filled dotted contours, $u_{h}=30,40,50, \ldots$ $\mathrm{m} \mathrm{s}^{-1}$ ), geopotential height (solid contours, $\Delta H=100 \mathrm{~m}$ ) and integrated precipitable water (filled solid contours, $W_{p}=0.5,1.0,1.5, \ldots \mathrm{mm}$ ), (c) raw horizontal divergence (contours $\quad \Delta \delta=5 \times 10^{-6} \mathrm{~s}^{-1}$ ) and (e) 100-km-smoothed horizontal divergence (contours $\Delta \delta=2 \times 10^{-6} \mathrm{~s}^{-1}$ ). The line indicates a cross section through Kühlungsborn $\left(54.1^{\circ} \mathrm{N}\right.$, $\left.11.8^{\circ} \mathrm{E}\right)$ shown for (b) wind speed $\left(u_{h}\right)$ and precipitation mixing ratio $\left(q_{p}=0.25,0.50\right.$, $0.75, \ldots \mathrm{g} \mathrm{kg}^{-1}$ ), (d) raw and (f) 100-km-smoothed divergence.
ACPD

7, 15873-15909, 2007

Impact of inertia-gravity waves on wind and precipitation

C. Zülicke and D. Peters

Title Page

Abstract

Introduction

Conclusions

References

Tables

Figures

14

$\rightarrow$

$<$

Back

Close

Full Screen / Esc

Printer-friendly Version

Interactive Discussion 


\section{(a)}

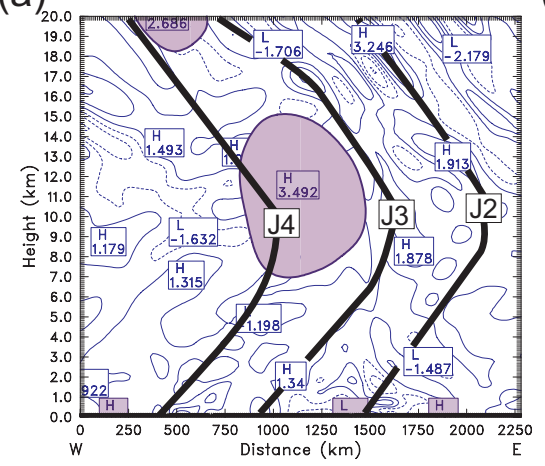

(c)

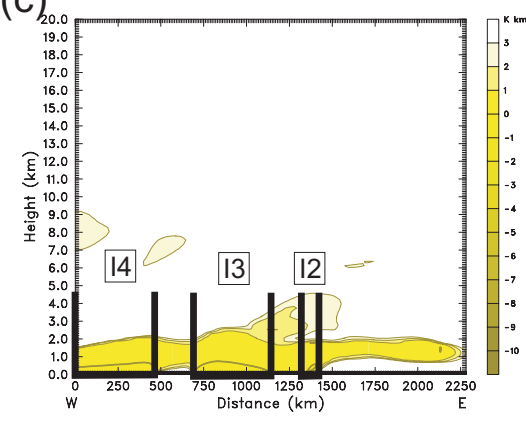

(b)
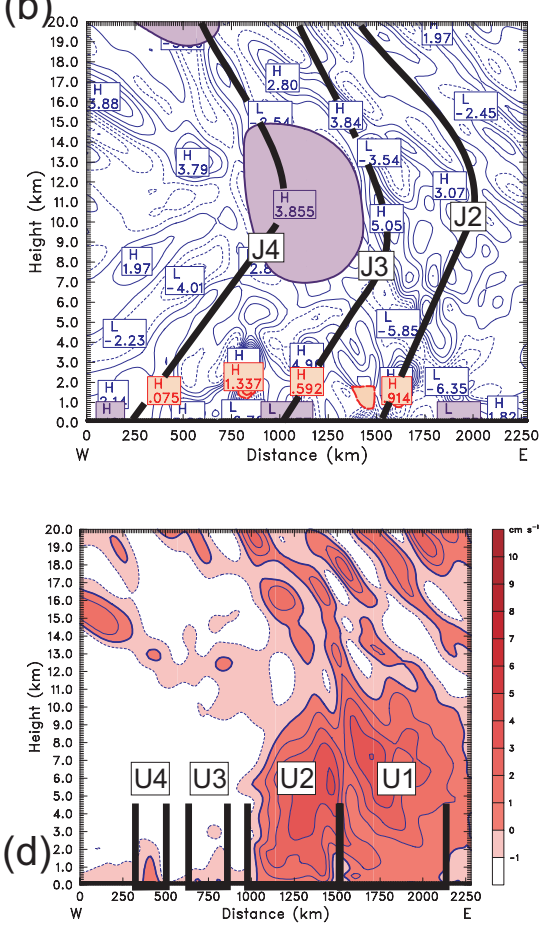

\section{ACPD}

7, 15873-15909, 2007

Impact of

inertia-gravity waves

on wind and

precipitation

C. Zülicke and D. Peters

Title Page

Abstract

Introduction

Conclusions

References

Tables

Figures

14

$\rightarrow$

4

Back

Close

Full Screen / Esc

Printer-friendly Version

Interactive Discussion below $3 \mathrm{~K} \mathrm{~km}^{-1}$ is shown (filled solid contours, $\partial \Theta_{e} / \partial z=3,2,1,0,-1, \ldots \mathrm{K} \mathrm{km}^{-1}$, the Zero contour drawn thick). (d) Vertical velocity above $-1 \mathrm{~cm} \mathrm{~s}^{-1}\left(w=-1,0,1, \ldots \mathrm{cm} \mathrm{s}^{-1}\right)$ is shown for the MM5DRY run. 
(a)

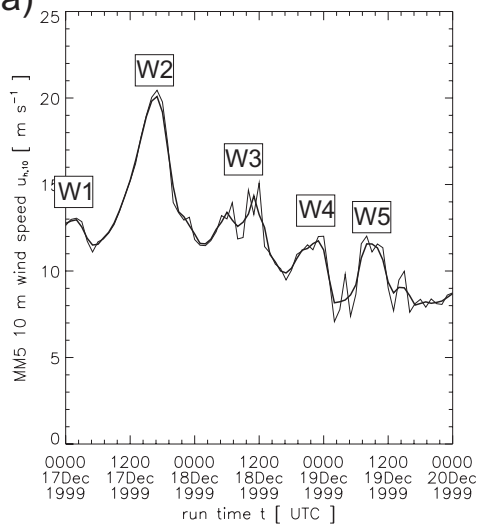

(c)

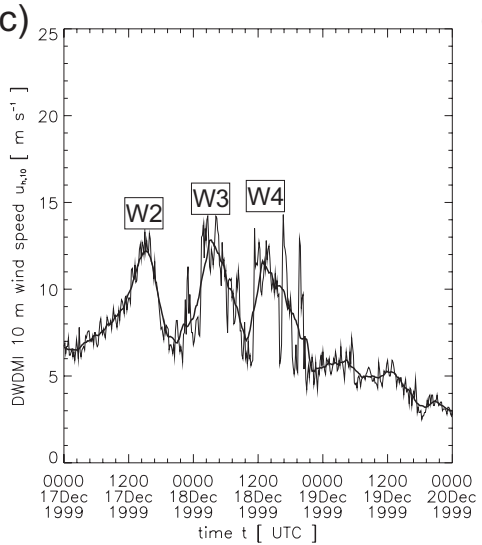

(b)

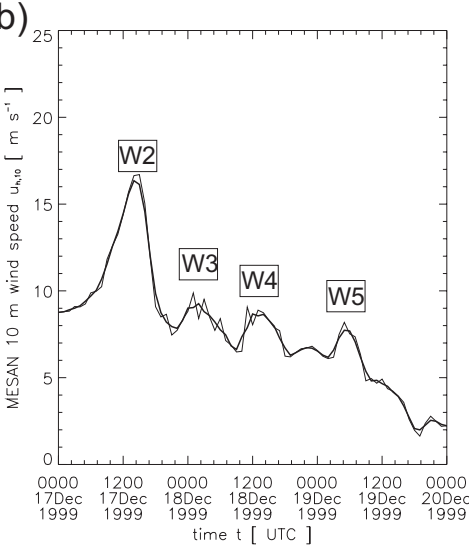

(d)

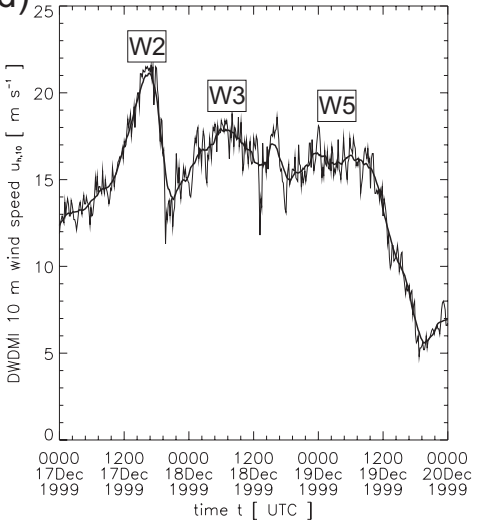

\section{ACPD}

7, 15873-15909, 2007

\section{Impact of}

inertia-gravity waves

on wind and

precipitation

C. Zülicke and D. Peters

Title Page

Abstract

Introduction

Conclusions

References

Tables

Figures

14

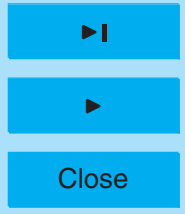

Back

Full Screen / Esc

Fig. 4. Wind speed time series at Warnemünde from (a) MM5, (b) MESAN, and (c) DWDMI with (d) Kap Arkona $\left(54.7^{\circ} \mathrm{N}, 13.4^{\circ} \mathrm{E}\right)$ data from DWDMI. The thin line is for original data; the bold line for $3 \mathrm{~h}$ averages.
Printer-friendly Version

Interactive Discussion 
(a)

(c)
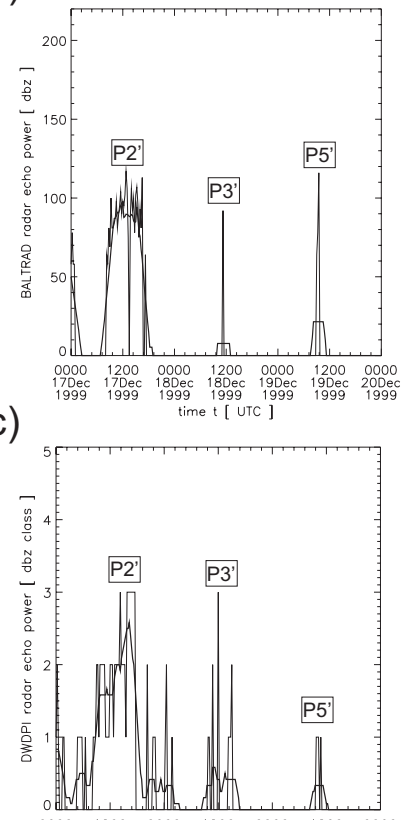

(e)

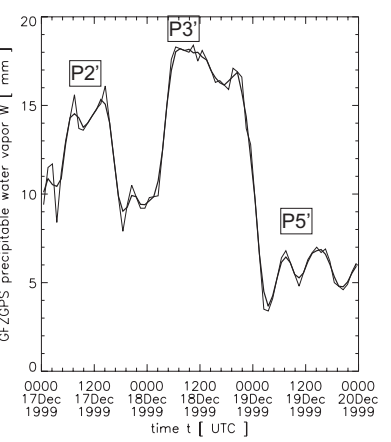

(b)

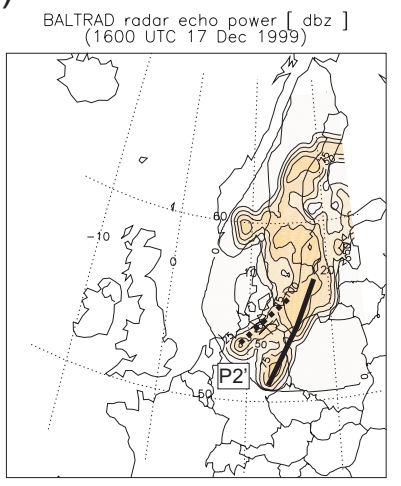

(d)

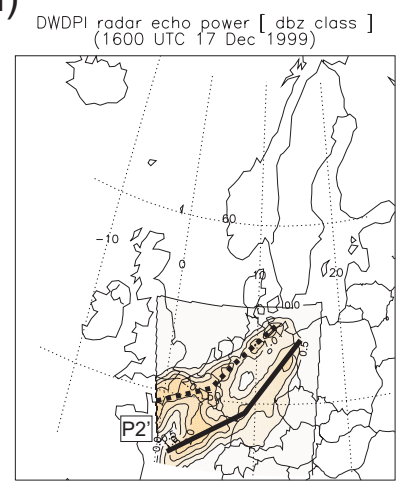

Fig. 5. Patterns in radar reflectivity. (a, c, e) Time series for Warnemünde of (a) BALTRAD radar reflectivity, (c) DWDPI radar reflectivity class and (e) GFZGPS precipitable water vapor $\left(W_{v}[\mathrm{~mm}]\right)$. (b, d) Maps for 16:00 UTC 17 December 1999 for (b) BALTRAD radar reflectivity and (d) DWDPI radar reflectivity class.

\section{ACPD}

7, 15873-15909, 2007

\section{Impact of}

inertia-gravity waves

on wind and

precipitation

C. Zülicke and D. Peters

Title Page

Abstract

Introduction

Conclusions

References

Tables

Figures

14

$\rightarrow$

4

Back

Close

Full Screen / Esc

Printer-friendly Version

Interactive Discussion 
(a)

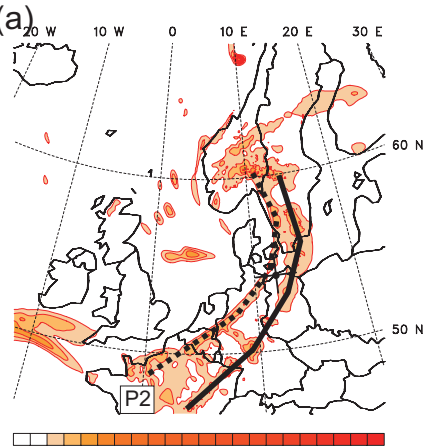

(c)

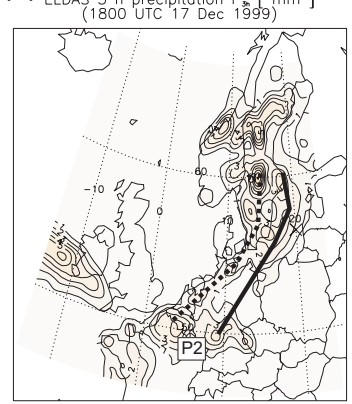

(e)

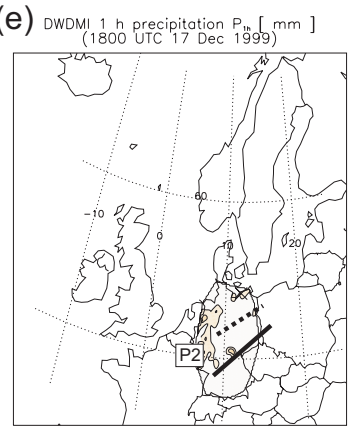

(b)

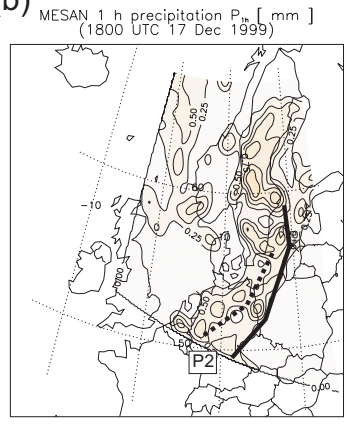

(d)

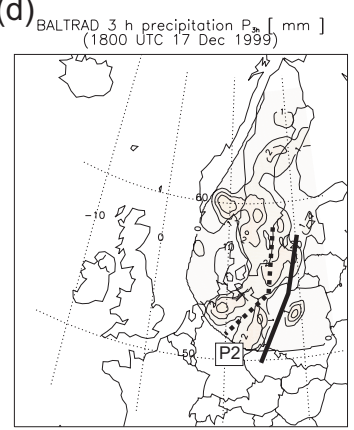

Fig. 6. Precipitation maps for 18:00 UTC 17 December 1999 (a) MM5 [mm (1 h $\left.)^{-1}\right]$, (b) MESAN [mm $\left.(1 \mathrm{~h})^{-1}\right]$, (c) ELDAS [mm (3h) ${ }^{-1}$ ], (d) BALTRAD [mm $\left.(3 \mathrm{~h})^{-1}\right]$ and (e) DWDMI $\left[\mathrm{mm}(1 \mathrm{~h})^{-1}\right]$.

ACPD

7, 15873-15909, 2007

\section{Impact of inertia-gravity waves on wind and precipitation}

C. Zülicke and D. Peters

Title Page

Abstract

Conclusions

Tables

14

Back

Full Screen / Esc

Printer-friendly Version

Interactive Discussion 
(a)

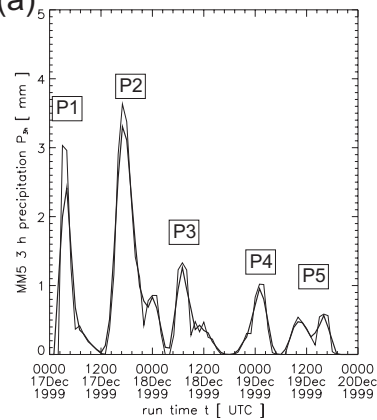

(c)

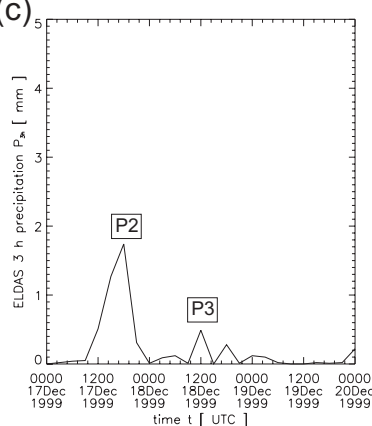

(e)

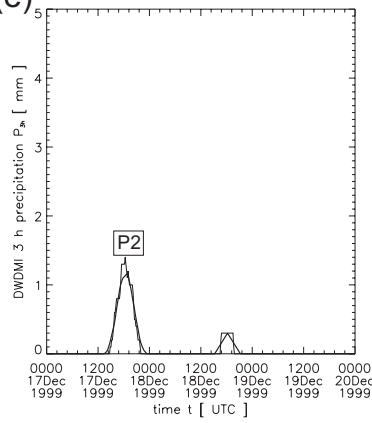

(b)

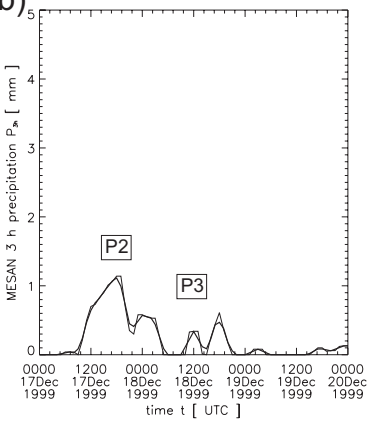

(d)

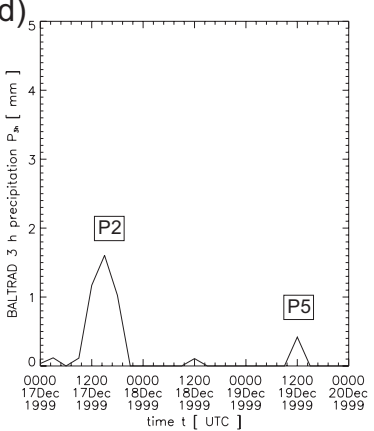

Fig. 7. Precipitation time series at Warnemünde $\left[\mathrm{mm}(3 \mathrm{~h})^{-1}\right]$ (a) MM5, (b) MESAN, (c) ELDAS, (d) BALTRAD and (e) DWDMI with (f) Kap Arkona data from DWMI.

ACPD

7, 15873-15909, 2007

\section{Impact of}

inertia-gravity waves

on wind and

precipitation

C. Zülicke and D. Peters

Title Page

Abstract

Introduction

Conclusions

References

Tables

Figures

14

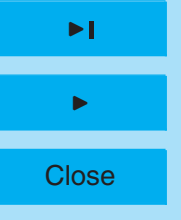

Back

Full Screen / Esc

Printer-friendly Version

Interactive Discussion 
(a)

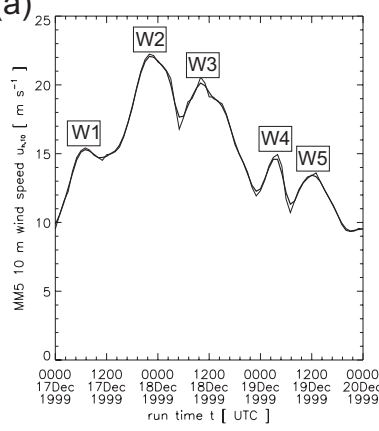

(c)

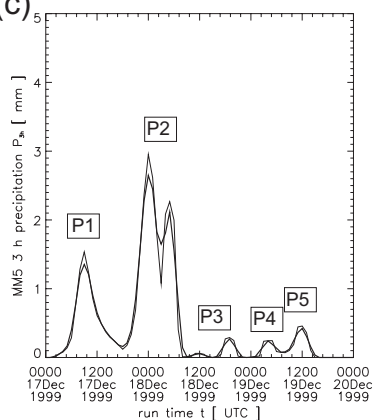

(e)

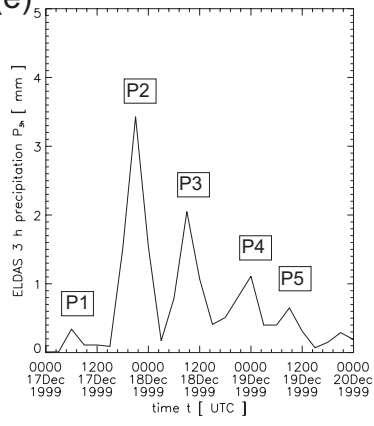

(b)

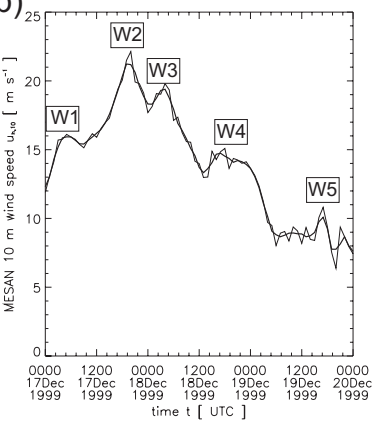

(d)

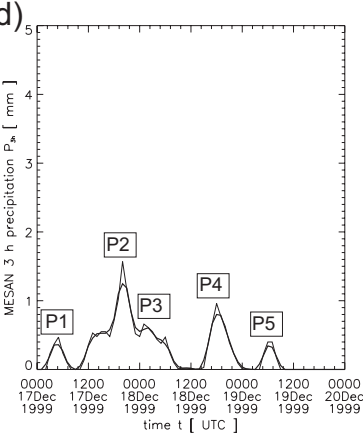

(f)

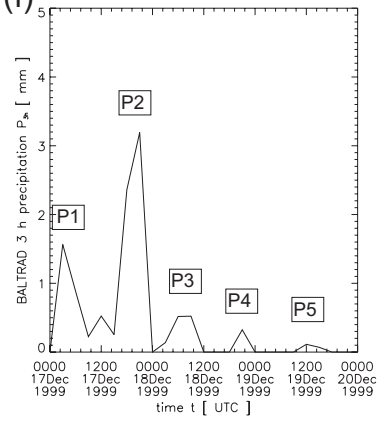

\section{ACPD}

7, 15873-15909, 2007

\section{Impact of}

inertia-gravity waves

on wind and

precipitation

C. Zülicke and D. Peters

Title Page

Abstract

Introduction

Conclusions

References

Tables

Figures

Fig. 8. Time series for the Gotland Basin (a) MM5 wind speed, (b) MESAN wind speed, (c) MM5 precipitation, (d) MESAN precipitation, (e) ELDAS precipitation and (f) BALTRAD precipitation.

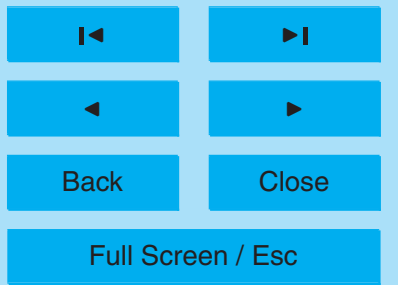

Printer-friendly Version

Interactive Discussion 


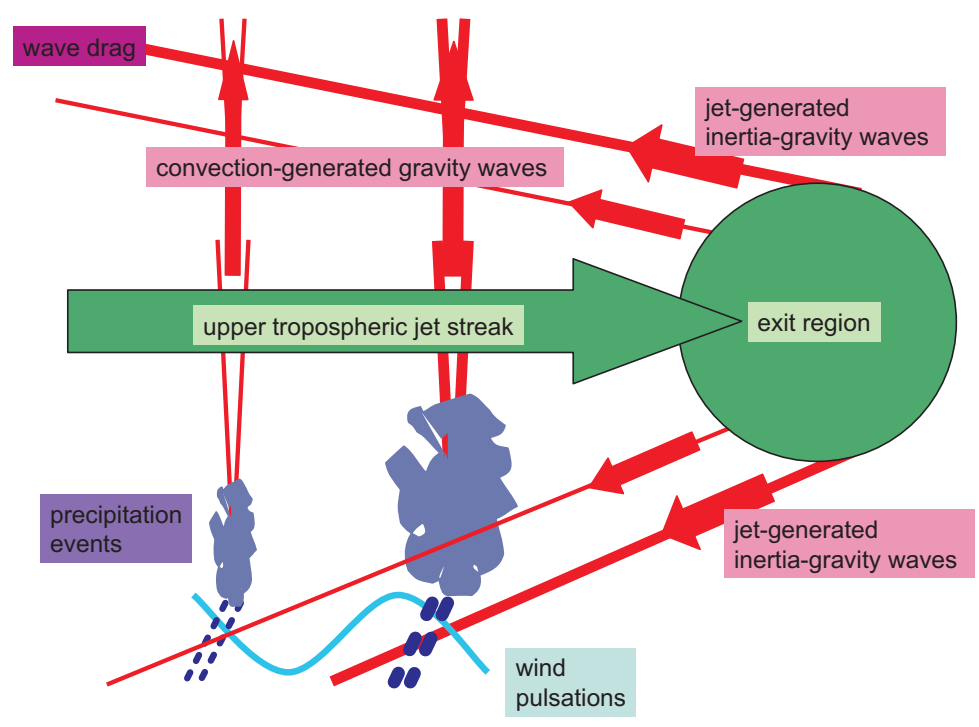

Fig. 9. Schematic sketch of the link between the upper and lower troposphere by inertia gravity waves as they were found during RWB. IGW packets are spontaneously radiated from the exit region of a jet streak at tropopause level (thin lines indicate locations of equal phase, thick arrows indicate group velocity). A part of them propagates upward into the stratosphere, another part goes down into the troposphere. Deep convection may be favored, which itself may induce additional gravity waves in the upper troposphere and further up. Related effects near the surface are wind pulsations and precipitation events while the wave drag is important for the middle atmosphere.

\section{Impact of \\ inertia-gravity waves \\ on wind and \\ precipitation}

C. Zülicke and D. Peters

\section{Title Page}

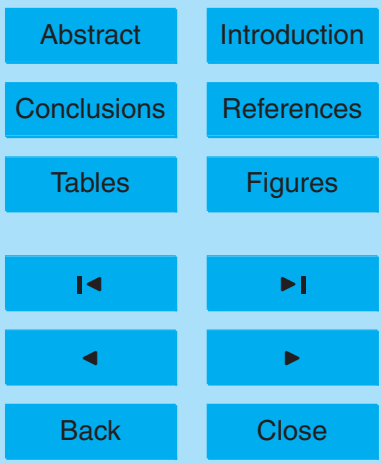

Full Screen / Esc

Printer-friendly Version

Interactive Discussion 